\title{
Counter-Rotating Tandem Motor Drilling System
}

\author{
Final Report
}

July 30, 2009

Prepared for:

U.S. Department of Energy

Project award number:

DE-FC26-05NT15489

\author{
Recipient: \\ Gas Technology Institute \\ 1700 S. Mt. Prospect Road \\ Des Plaines, IL 60018 \\ Project Director: \\ Kent F. Perry \\ Executive Director \\ Exploration and Production Research
}

July 30, 2009 


\section{Table of Contents}

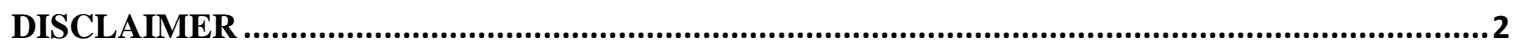

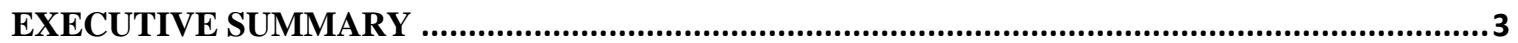

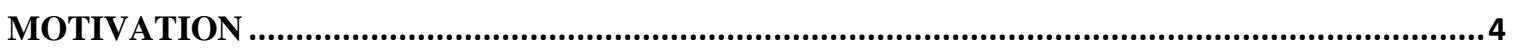

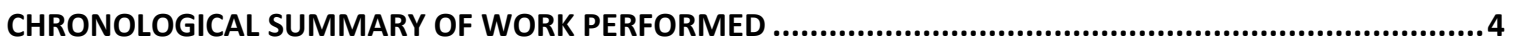

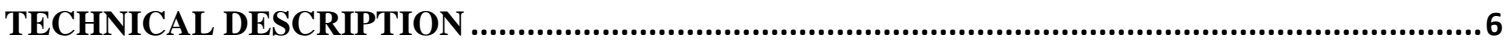

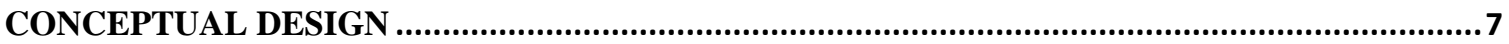

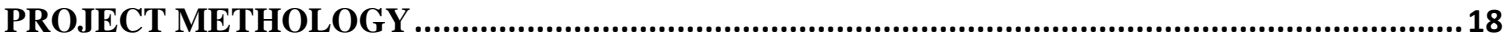

RESULTS AND DISCUSSION OF THE MAJOR TECHNICAL PROBLEMS ENCOUNTERED ...............................19

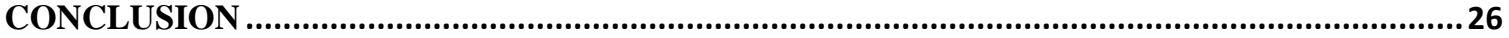

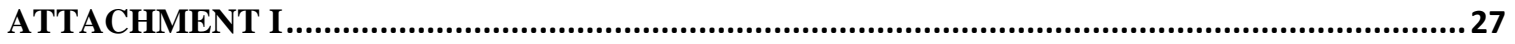

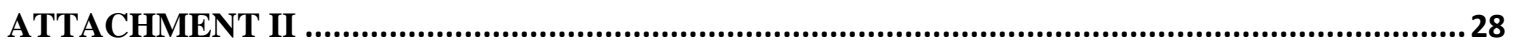

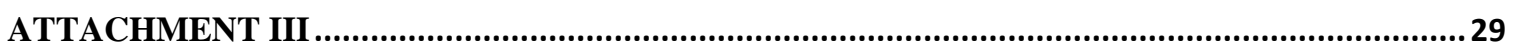

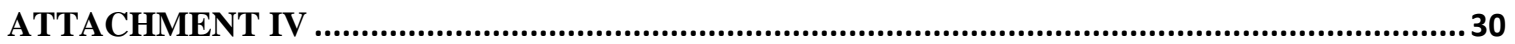

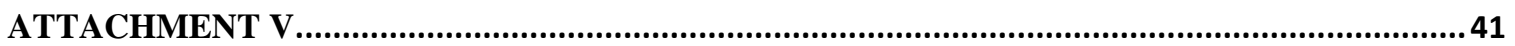

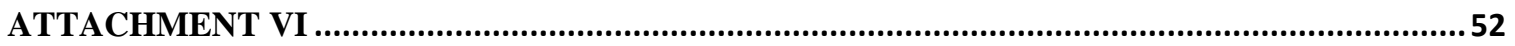

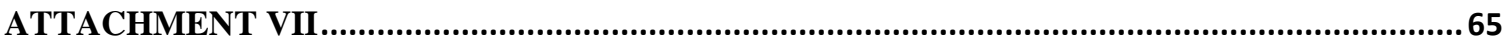




\section{DISCLAIMER}

This final report was prepared as an account of work sponsored by an agency of the United States Government. Neither the United States Government nor any agency thereof, nor any of their employees, makes any warranty, express or implied, or assumes any legal liability or responsibility for the accuracy, completeness, or usefulness of any information, apparatus, product, or process disclosed, or represents that is use would not infringe privately owned rights. Reference herein to any specific commercial product, process, or service by trade name, trademark, manufacturer, or otherwise does not necessarily constitute or imply its endorsement, recommendation, or favoring by the United States Government or any agency thereof. The views and opinions of authors expressed herein do not necessarily state or reflect those of the United States Government or any agency thereof. 


\section{EXECUTIVE SUMMARY}

Gas Technology Institute (GTI), in partnership with Dennis Tool Company (DTC), has worked to develop an advanced drill bit system to be used with microhole drilling assemblies. One of the main objectives of this project was to utilize new and existing coiled tubing and slimhole drilling technologies to develop Microhole Technology (MHT) so as to make significant reductions in the cost of E\&P down to 5000 feet in wellbores as small as 3.5 inches in diameter. This new technology was developed to work toward the DOE's goal of enabling domestic shallow oil and gas wells to be drilled inexpensively compared to wells drilled utilizing conventional drilling practices.

Overall drilling costs can be lowered by drilling a well as quickly as possible. For this reason, a high drilling rate of penetration is always desired. In general, high drilling rates of penetration (ROP) can be achieved by increasing the weight on bit and increasing the rotary speed of the bit. As the weight on bit is increased, the cutting inserts penetrate deeper into the rock, resulting in a deeper depth of cut. As the depth of cut increases, the amount of torque required to turn the bit also increases.

The Counter-Rotating Tandem Motor Drilling System (CRTMDS) was planned to achieve high rate of penetration (ROP) resulting in the reduction of the drilling cost. The system includes two counter-rotating cutter systems to reduce or eliminate the reactive torque the drillpipe or coiled tubing must resist. This would allow the application of maximum weight-on-bit and rotational velocities that a coiled tubing drilling unit is capable of delivering.

Several variations of the CRTDMS were designed, manufactured and tested. The original tests failed leading to design modifications. Two versions of the modified system were tested and showed that the concept is both positive and practical; however, the tests showed that for the system to be robust and durable, borehole diameter should be substantially larger than that of slim holes. As a result, the research team decided to 
complete the project, document the tested designs and seek further support for the concept outside of the DOE.

\section{MOTIVATION}

The principal motivation behind the project was the increasing of natural gas supply available to the US with minimal environmental impact by decreasing the cost and footprint of drilling operations for slim holes (3 1/2inchs) at relatively shallow depths. The Counter-Rotating Tandem Motor Drilling System (CRTMDS) was specifically directed toward gas reserves in unconventional or low-permeability formations in which a large number of wells are necessary to effectively drain the reservoir. Drilling costs would be lowered as well through the development of an improved drilling system suitable for coiled tubing drilling. Current coiled tubing drilling systems are able to drill at relatively low cost and with improved environmental characteristics as compared with conventional drilling rigs. However, coiled tubing drilling would have a much greater impact on the development of unconventional gas if the rate of penetration could be increased by $25-60 \%$, decreasing the drilling cost by up to $40 \%$.

\section{CHRONOLOGICAL SUMMARY OF WORK PERFORMED}

Year 2005: Before any fabrication of the CRTDMS (3 $1 / 2$ reamer), a similar but smaller tool (2 5/8” Reamer) from Los Alamos National Laboratories (LANL) was tested at the Rocky Mountain Oilfield Testing Center (RMOTC). When compared with conventional bits at the same test site, the LANL tool achieved 4 to 8 times faster penetration. Results from this test generated some impressive support of the overall tool design and concept. (See attachment IV for more details).

Year 2006: Due to manufacturing delays of the new CRTMDS $3 \frac{1 / 2}{2}$ reamer tool, a test with the Los Alamos tool (2 5/8” reamer) was performed in GTI’s Catoosa site. First attempt on June 6 was stopped because the well was deviated. Second attempt was performed June 15 and the CRTMDS drilled to a depth of 382' with a very low rate of penetration. Unusual vibration, appearance of rubber debris in the flow line screen, and 
low rate of penetration were noticed. Because of these observations the bottom hole assembly was pull out of the hole and the damages examined. No damage in any of the internal parts of the system was observed but parts of the tool surface showed signs or erosion. (See Attachment V for more details).

Year 2007: Manufacturing of the $31 / 2$ " reamer CRTDMS was completed and the tool tested at Catoosa. The CRTMDS drilled to a depth of $402 \mathrm{ft}$. At this point a significant drop in the surface pressure was noticed. The tool was pulled out to examine. It was noticed that part of the BHA had backed-off downhole. The test proved that the counterrotating tandem motor system can effectively drill with a high rate of penetration and low weight on bit. However, the tool failure indicated that better methods for limiting lefthand torque, limiting vibration, and securing downhole connections were needed. (See Attachment VI for more details).

Year 2008: A detailed design for a new CRTMDS was developed and the tool fabricated. This design was similar to the design tested for Los Alamos National Laboratory (LANL) in September 2005 at the Rocky Mountain Oilfield Testing Center. Several tests were performed at GTI's Catoosa test site. These tests showed that although high penetration rates were easily achieved, the tool twisted off between the two counter rotating cutter systems. A new design was proposed and developed.

Year 2009: The new design was completed. This new tool has a motor that develops significant torque in a short length and does not contain the typical failure prone rubber or urethane stator components. On March 16, 2009 the tool was tested at GTI Catoosa site. The test revealed that because of the tight tolerance, solid particles in conventional drilling fluids caused jamming of the motor. To overcome this problem, a 10 micron filter was added to the string and test repeated but results from this modification were also negative. (See Attachment VII for more details). 


\section{TECHNICAL DESCRIPTION}

The Counter-Rotating Tandem Motor Drilling System was designed to aid in achieving higher rate of penetration (ROP) with a coiled tubing system. In general, high drilling rates of penetration can be achieved by increasing the weight on bit, increasing the amount of torque on the bit, and increasing the rotary speed of the bit.

The GTI/DTC drill bit is a revolutionary advancement over conventional drill bits in 3 ways:

- A smaller left-handed pilot bit drills a small pilot hole, while a right-handed reamer bit removes additional material and enlarges the hole to its final diameter.

- The combination of the left and right-handed torques compensate one another reducing the amount of torque on coiled tubing while assuring that the hole remains straight.

- Specialty PDC cutter heads with a microwave-sintered carbide substrate developed by Dennis Tool Company have a 56\% greater life than conventional bits, such that bit changes are much reduced.

Downhole positive displacement motors (PDM's) are commonly used on conventional coiled tubing drilling systems to convert hydraulic power into mechanical power for driving the drill bit. PDM's can provide the high rotary speeds and high torque needed for driving the drill bit through the formation. However, the reactive torque created by drilling can cause torsional deflection in the coiled tubing. When the reactive torque from drilling is high enough, the coiled tubing can twist and even shear in half. This is of special concern when using small diameter coiled tubing, as is the case for microhole drilling. The amount of torque that the coiled tubing can safely handle limits the potential for drilling at higher rates of penetration.

A conventional coiled tubing bottom hole assembly (BHA) consists of a single bit and positive displacement motors (PDM), which is used to drill the entire hole size. The proposed CRTMDS tool offers a revolutionary advancement in drilling mechanics as compared to conventional methods. The CRTMDS uses a left-hand turning PDM to drill a small pilot bit with left-hand rotation. Above this assembly is a second PDM which drives a reamer or hole opener in a right-hand direction. The torque generated from the left-handed pilot bit counteracts the torque generated by the right-handed reamer. If the 
cutting structure and rotary speed of the pilot bit and reamer are properly balanced, the result is a net of zero reactive torque. In effect, there is very little torque transmitted to the coiled tubing. This will enable the use of higher torque PDM's on the pilot bit and reamer, without exceeding the torque limitations of the coiled tubing. The use of the higher torque PDM's will increase the drilling rate of penetration of the tool.

It is widely accepted that for a given weight on bit (WOB) and rotary speed, a smaller diameter bit will drill at a higher ROP than a larger diameter bit with a similar cutting structure. This implies that the small pilot bit on the CRTMDS would drill faster than a conventional bit drilling a full gage hole. Another advantage of the proposed tool is that the pilot bit drills ahead of the reamer or hole opener. The removal of the rock in the pilot hole relieves some of the rock's compressive stress near the periphery of the hole. This allows the reamer to drill rock that is in an "unconfined" state, thereby improving the drilling efficiency of the tool. As a result, less weight on bit will be required to obtain a given ROP. This is beneficial for coiled tubing applications, because the amount of weight that can be applied to the BHA is limited.

Reaming while drilling is a common practice in conventional size oil and gas well drilling programs, due to improved drilling efficiency. For these larger hole sizes, the bit is turned by a PDM or turbine, and the reamer is turned by the rotation of the drill string. Rotating the drill string is not an option in coiled tubing applications. In addition to drilling with low reactive torque, the CRTMDS also provides the drilling efficiency benefits of reaming while drilling using coiled tubing leading to higher ROP. Positive Displacement Motors of various sizes are currently available from several manufacturers, but all turn in a conventional right-hand direction. A left-hand turning PDM was designed and manufactured through this project.

\section{CONCEPTUAL DESIGN}

The proposed CRTMDS tool (Figure 1) consists of the following components: 2-1/4" left-hand pilot bit with polycrystalline diamond compact (PDC) cutting inserts; 1-11/16 " 1:2 lobe, 3 stage left-hand turning PDM; 3-1/2" right-hand reamer/stabilizer with PDC cutters; 2-3/8” 1:2 lobe, 7 stage right-hand turning PDM. 
Figure 2 shows a 2.250” diameter lefthand turning pilot bit with fourteen PDC cutters on the drilling face. The PDC cutting elements are 0.252 " diameter $\mathrm{x} 0.315$ ” tall, oriented at a $30^{\circ}$ back rake angle. This back rake angle prevents impact damage to the cutters while still allowing for aggressive drilling and a high rate of penetration. Also included in the pilot bit design are four PDC gage trimmers and twenty tungsten carbide gage buttons. These elements will aid the drilling stability of the tool; limiting the sidecutting ability and helping the pilot bit drill an ingauge hole.

Figure 2 - Left-Hand Turning Pilot Bit

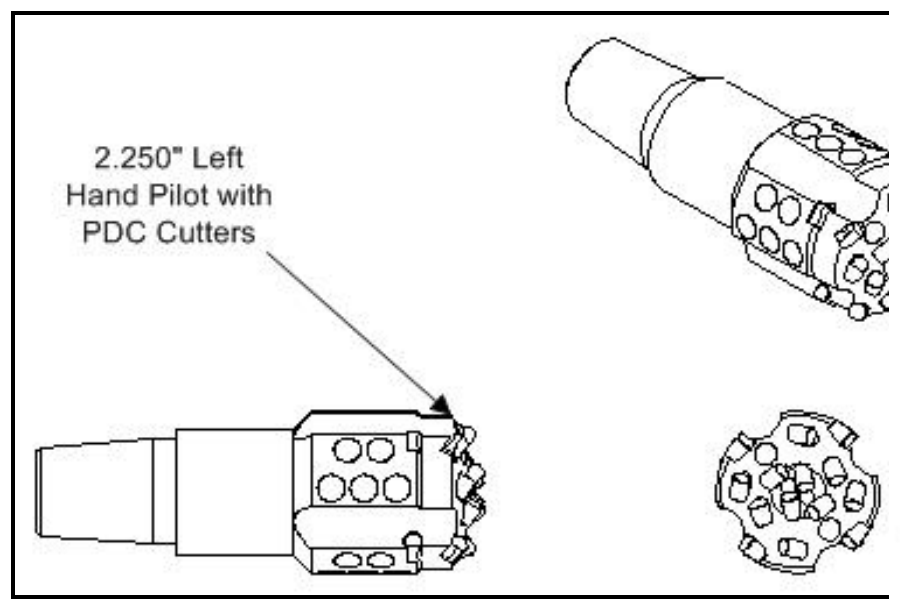

Figure 3 depicts the design for the 3.500” diameter right-hand turning reamer 2.188” spiral stabilizer. Like the pilot bit, the reamer also utilizes 0.252" diameter x 0.315” tall PDC cutting inserts at $30^{\circ}$ back rake. The drawing on
Figure 1 - CRTMDS BHA Assembly

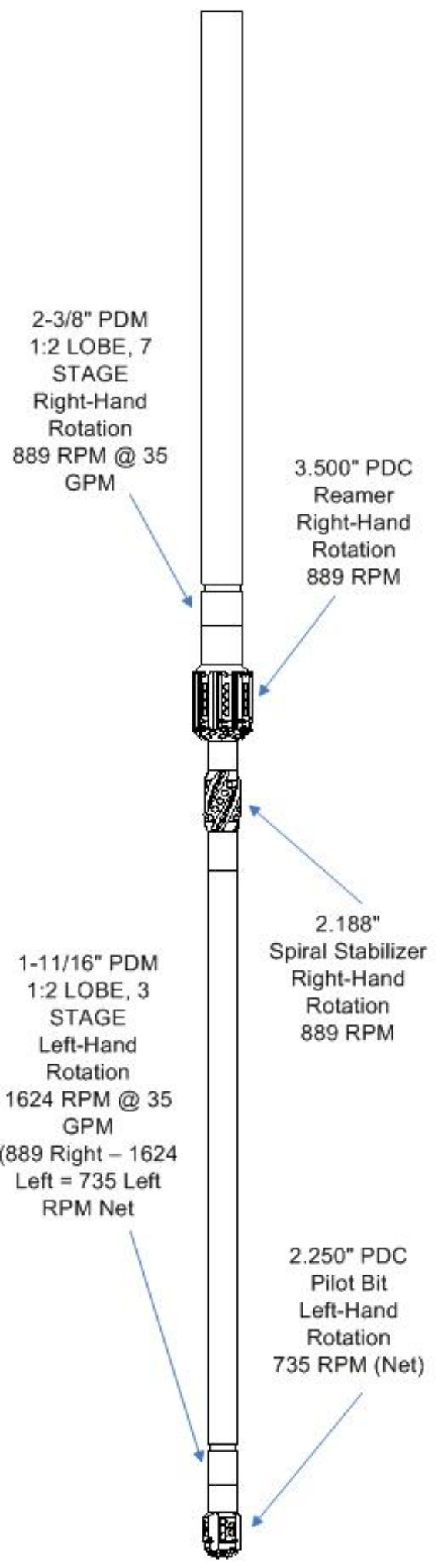


Figure 3 shows twenty-four cutting inserts on the drilling face, eight gage trimmers, and thirty-two tungsten carbide gage buttons. An additional feature shown on the reamer is back-reaming PDC cutting inserts. These cutters will allow the tool to back ream as the bottom hole assembly (BHA) is pulled out of the borehole. This will help prevent the tool from getting stuck in formations that swell after initial drilling. It will also help ensure an in-gage borehole.

Figure 3 - Pilot Reamer

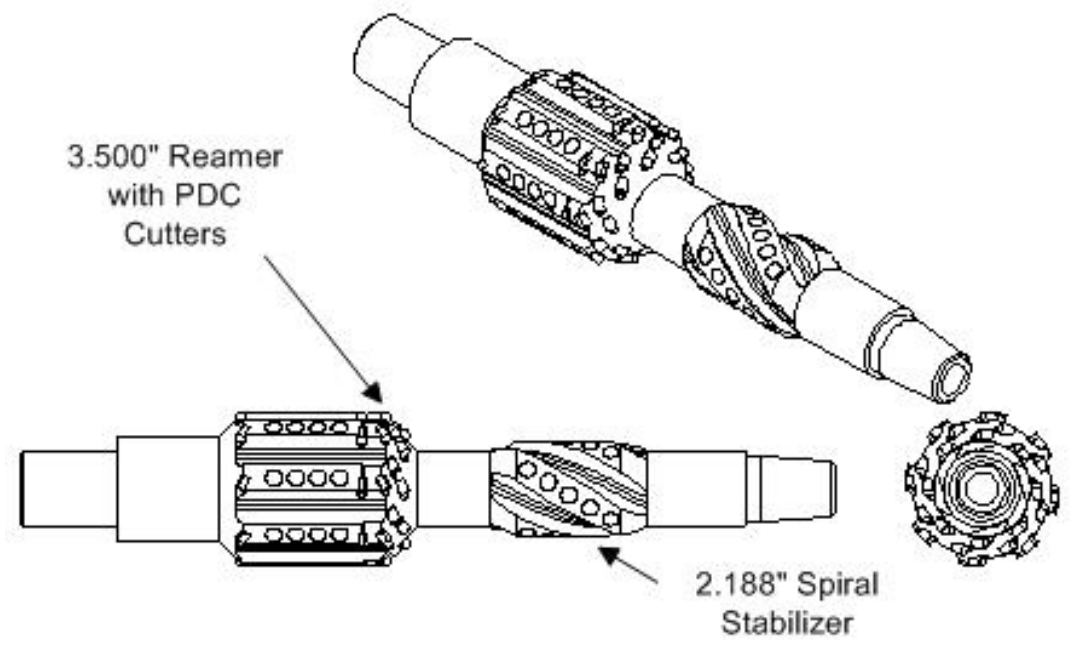

Another feature shown in Figure 3 is the integral spiral stabilizer. The stabilizer will guide the reamer into the hole drilled by the pilot bit. It will help ensure stable drilling performance.

The other major components in the tool are the right and left hand turning positive displacement motors (PDM's). The right-hand turning motor is a stock item available off the shelf from several different PDM suppliers. Initial calculations indicate that a 2-3/8" 1:2 lobe, 7 stage PDM will be required. The left-hand turning motor is similar to a conventional motor, with the exception of modifications required to allow for left-hand rotation. These modifications include a left-hand rotor and stator, and left-hand connections to keep the tool from un-screwing during use. Initial calculations suggested that a 1-11/16” 1:2 lobe, 3 stage left-hand turning PDM would be needed.

At a flow rate of 35 gallons per minute, the 2-3/8” PDM and the right-handed reamer will rotate at about $889 \mathrm{rpm}$ to the right. At this same flow rate, the left-hand 111/16” PDM will rotate at about 1624 rpm to the left. Subtracting the 889 rpm right from the 1624 left-hand rpm gives a net left-hand rotation of $735 \mathrm{rpm}$ for the left-hand pilot 
bit. As discussed in the section on Engineering Design and Application Specification, the application of these rotational speeds satisfies the requirements for equal rate of penetration for the pilot and reamer bits and creates compensating torques with nearly zero net torque on the drilling string. A brief description of mathematical derivation of torque and penetration rate is given on pages 12 to 17 . However, it should be noted that the BHA torque equilibrium; i.e., left and right torques of nearly equal magnitudes, would be disturbed in cases where the mechanical properties of the formation being drilled with the pilot bit would be different from those of the formation being reamed as would be the case when crossing formation interfaces.

\section{Raw Materials or Components used to Manufacture Equipment}

The tool bodies for pilot bit, reamer, and stabilizer are machined from 4340 heattreated steel. This material is commonly used in oilfield drilling applications because of its high strength, good erosion resistance, and compatibility with braze alloys used to attach the PDC cutters to the tool. The PDC cutting inserts are the premium cutters manufactured by Dennis Tool Company. The carbide substrates for the PDC inserts are manufactured with a new microwave sintering process. The microwave sintering process results in carbide with superior mechanical properties (wear resistance and impact resistance) as compared to conventionally sintered carbide. The end result is improved PDC cutter life over cutters manufactured with conventional methods. This adds longevity to the drilling tool. Premium PDC cutting inserts and tungsten carbide gage inserts are brazed into the steel tool bodies.

\section{Engineering Design and Application Specifications}

The specifications of the CRTMDS were designed to be consistent with the MHT goal of "drilling and completing reservoirs at a minimum of 2,000 feet TVD and 1,000 feet directional displacement in a $3 \frac{1}{2}$ " borehole", as specified in Section 1.3 of the RFP the project was selected under. These specifications follow:

\section{Tool Dimensions:}

Total tool weight: 208 pounds

15489R08

GTI Principal Investigator: Kent Perry
Total tool length: 23 feet

GTI Project 20199

July 30, 2009 


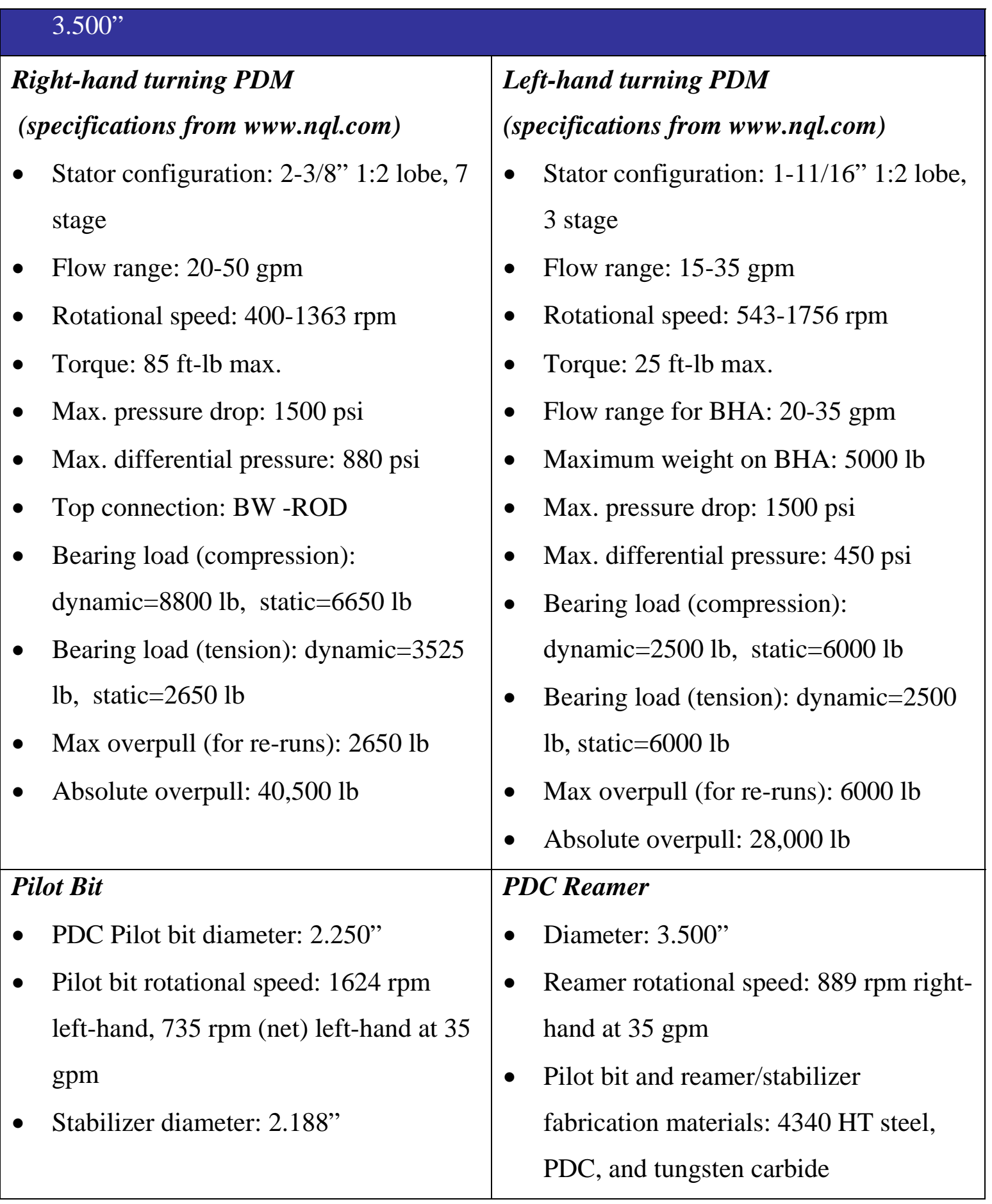

Basic Design Calculations to Support Conceptual Specifications and Show How the Equipment will Work in Theory.

As discussed earlier, high drilling rates of penetration can be achieved by increasing the weight on bit (WOB), increasing the amount of torque on the bit, and 
increasing the rotary speed of the bit. Increasing WOB causes the cutting inserts to penetrate deeper into the rock, resulting in a deeper depth of cut. As the depth of cut increases, the amount of torque required to turn the bit also increases. In effect, the amount of torque that the coiled tubing can safely handle is the rate limiting element for ROP with coiled tubing systems.

The following calculations are used to determine the bit size, reamer size, cutting structure, and rotary speeds required to design a pilot bit and reamer that will drill with nearly equal, but opposite, torque and similar rates of penetration.

\section{Assumptions}

1. The weight applied to the tool will be applied proportionally to the pilot bit and reamer based on the respective borehole area of the pilot bit and reamer.

2. Depth of cut is controlled by WOB and the number of cutters on the face of the bit or reamer. For a given weight on bit, increasing the number of cutters will decrease the depth of cut.

3. The shear strength of the rock remains constant.

4. The radial area of cut can be approximated by a rectangular cross-section.

5. The torque required to turn the pilot bit or reamer is proportional to the depth of cut and the radial distance from the axis of rotation (torque $=$ force $\mathrm{x}$ distance, where force is a function of depth of cut and shear strength of the rock). For a given weight on bit, the torque required can be decreased by decreasing the depth of cut, or decreasing the radial distance from the axis of rotation.

6. The rate of penetration for a given depth of cut is proportional to the rotary speed. For a given depth of cut, ROP can be increased by increasing the rotary speed. 


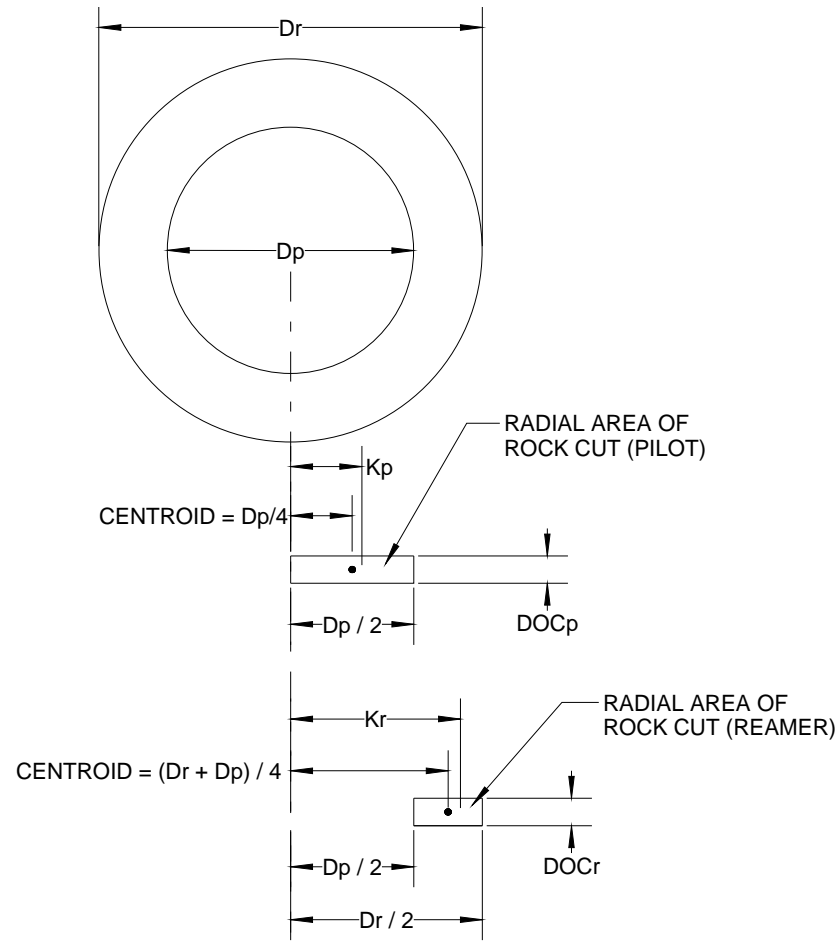

Figure 4. Schematic Diagram Showing Parameters Considered in Calculating Forces Involved in CRTMDS Drilling

The total borehole area $\left(\mathrm{A}_{\text {Tот }}\right)$, pilot borehole area $\left(\mathrm{A}_{\mathrm{P}}\right)$, and reamer borehole area $\left(A_{R}\right)$ can be calculated as follows:

$$
\begin{aligned}
& A_{\text {TOT }}=\pi\left(D_{R} / 2\right)^{2} \\
& A_{P}=\pi\left(D_{P} / 2\right)^{2} \\
& A_{R}=A_{T O T}-A_{P}
\end{aligned}
$$

where $D_{P}$ and $D_{R}$ area the diameters of the pilot bit and reamer, respectively.

Assuming that the total weight on the bottom hole assembly (WOB $\mathrm{WOT}_{\text {Tо }}$ ) is applied proportionally to the pilot bit $\left(\mathrm{WOB}_{\mathrm{P}}\right)$ and reamer $\left(\mathrm{WOB}_{\mathrm{R}}\right)$ based on the respective borehole areas:

$$
\begin{aligned}
& W O B_{P}=\left(A_{P} / A_{T O T}\right)\left(W O B_{T O T}\right) \\
& W O B_{R}=\left(A_{R} / A_{T O T}\right)\left(W O B_{T O T}\right)
\end{aligned}
$$

Assuming the depth of cut (DOC) is proportional to WOB and inversely proportional to the number of cutters on the drilling face: 


$$
\begin{aligned}
& \mathrm{DOC}_{P} \sim \mathrm{WOB}_{P} / \text { (\# of cutters on pilot face) (eq. 6) } \\
& \mathrm{DOC}_{R} \sim \mathrm{WOB}_{R} /(\text { \# of cutters on reamer face) }
\end{aligned}
$$

Torque $(T)$ is equal to the product of cutting force $(F)$ and radial distance $(R)$ from the axis of rotation. For the pilot bit and reamer, the respective torques can be calculated by:

$$
\begin{aligned}
& T_{P}=F_{P} \times R_{P} \\
& T_{R}=F_{R} \times R_{R}
\end{aligned}
$$

Assuming that the cutting force $(\mathrm{F})$ is proportional to the product of the radial area of rock cut (AC) and the shear strength of the rock $(\tau)$ :

$$
F \sim A C \times \tau
$$

Since the shear strength of the rock $(\tau)$ is assumed to be constant, we assume that the cutting force is proportional to the radial area of rock cut:

$$
F \sim A C
$$

For simplicity, the radial area cut (AC) will be assumed to have a rectangular cross section. This area can be calculated by multiplying the base of the area by the height of the area:

$$
\begin{aligned}
A C_{P}= & \left(D_{P} / 2\right)\left(D O C_{P}\right) \\
& A C_{R}=\left[\left(D_{R} / 2\right)-\left(D_{P} / 2\right)\right]\left(D O C_{R}\right)
\end{aligned}
$$

Substituting eqs. 12 and 13 into eq. 11, the cutting forces for the pilot bit $\left(\mathrm{F}_{\mathrm{P}}\right)$ and reamer $\left(F_{R}\right)$ may be calculated by:

$$
F_{P} \sim\left(D_{P} / 2\right)\left(D O C_{P}\right)
$$




$$
F_{R} \sim\left[\left(D_{R} / 2\right)-\left(D_{P} / 2\right)\right]\left(D O C_{R}\right)
$$

In order to calculate the torque for the pilot bit and reamer, cutting force and the radial distance from the axis of rotation are required. Since the cutting force is applied over an area, rather than at a single point, this radial distance is not constant. The radius of gyration of an area is defined as distance $(\mathrm{K})$ from the axis. At this distance, $\mathrm{K}$, an equivalent area is thought of as a line area parallel to the original axis. The moment of inertia of this line area is unchanged. The parallel axis theorem can be used to calculate the radius of gyration of the area about the tool axis of rotation. For a rectangular area of cut the radius of gyration $(k)$ about the tool axis is defined as:

$$
k=\sqrt{\frac{\frac{1}{12} b^{3} h}{b h}+d^{2}}
$$

where $b$ is the base of the rectangular area, $h$ is the height of the rectangular area, and $d$ is the distance from the centroid of the area to the axis of rotation. This equation simplifies to:

$$
k=\sqrt{\frac{1}{12} b^{2}+d^{2}}
$$

For the pilot bit, the radius of gyration of the radial cut area about the tool axis is:

$$
k_{P}=\sqrt{\frac{1}{12}\left(D_{P} / 2\right)^{2}+\left(D_{p} / 4\right)^{2}}
$$

For the reamer, the radius of gyration of the radial cut area about the tool axis is:

$$
k_{R}=\sqrt{\frac{1}{12}\left[\left(D_{R} / 2\right)-\left(D_{p} / 2\right)\right]^{2}+\left[\left(D_{R}+D_{P}\right) / 4\right]^{2}}
$$

Substituting $k_{p}$ for $R_{P}$ into eq. 8 , the torque required to turn the pilot bit is: 


$$
T_{P} \sim\left(D_{P} / 2\right)\left(D O C_{P}\right) \sqrt{\frac{1}{12}\left(D_{P} / 2\right)^{2}+\left(D_{P} / 4\right)^{2}}
$$

Substituting $k_{R}$ for $R_{R}$ into eq. 9, the torque required to turn the reamer is:

$$
T_{R} \sim\left[\left(D_{R} / 2\right)-\left(D_{P} / 2\right)\right]\left(D O C_{R}\right) \sqrt{\frac{1}{12}\left[\left(D_{R} / 2\right)-\left(D_{P} / 2\right)\right]^{2}+\left[\left(D_{R}+D_{P}\right) / 4\right]^{2}}
$$

For the desired condition of balanced torque for the pilot bit and reamer, the ratio of the pilot bit torque to the reamer torque should be close to 1:1.

$$
\frac{T_{P}}{T_{R}} \approx 1 \quad \text { (eq.22) }
$$

The rotary speed of the right-handed reamer is $\left(N_{R}\right)$. The specific rotary speed of the pilot bit is $\left(N_{P}\right)$. The net rotary speed of the left-hand pilot bit $\left(N_{P N E T}\right)$ is calculated as:

$$
N_{P N E T}=N_{P}-N_{R}
$$

The rate of penetration (ROP) equals the product of depth of cut (DOC) and the rotary speed $(N)$ :

$$
\begin{aligned}
& R O P_{P}=\left(D O C_{P}\right)\left(N_{P N E T}\right) \\
& R O P_{R}=\left(D O C_{R}\right)\left(N_{R}\right)
\end{aligned}
$$

For the desired condition of balanced ROP for the pilot bit and reamer, the ratio of the ROP's should be close to 1:1.

$$
\frac{R O P_{P}}{R O P_{R}} \approx 1
$$

The desired diameter for the reamer is 3.500". Approximately twenty-four PDC cutters (0.252” diameter x 0.315 ” tall) will fit on the reamer face. Choosing a pilot bit diameter of 2.250" with fourteen PDC cutters on the bit face and plugging these values into the torque equations yields: 


$$
\frac{T_{P}}{T_{R}}=0.974
$$

The ratio is close to a value of 1 , which indicates that a 2.250" diameter left-hand pilot bit with fourteen PDC cutters on the face will drill with nearly equal but opposite torque to a 3.500" reamer with twenty-four PDC cutters on the face. This satisfies the desired condition of low net reactive torque transmitted to the coiled tubing.

In order to obtain a balanced ROP for the pilot bit and reamer, right and left-hand turning PDM's with the proper operating speeds at the same flow rate must be chosen. A stock item right-hand turning 2-3/8” 1:2 lobe, 7-stage PDM has a rotary speed of 889 rpm @ 35 gallons per minute. A stock item 1-11/16” 1:2 lobe, 3-stage PDM has a rotary speed of 1624 rpm @ 35 gallons per minute. It will be modified to rotate in a left-hand direction. Plugging these values into the ROP equations yields:

$$
\frac{R O P_{P}}{R O P_{R}}=0.998
$$

The ratio is very close to a value of 1 , which indicates that the pilot bit and reamer as described above, with the motors described above will drill at about the same ROP. This satisfies the desired condition of nearly equal ROP for the pilot bit and reamer. 


\section{PROJECT METHOLOGY}

The project was divided into six tasks, (1) conceptual design, (2) final design, (3) prototype fabrication; (4) bit testing, (5) compilation of lessons learned, and (6) final design and fabrication. The project team was structured to provide the necessary leadership and support for each phase. Kent Perry of GTI ran the overall project, with support from Mahlon Dennis of Dennis Tool Company. Figure 5 shows the project organization. The individuals leading each stage of the project are identified in the boxes on Figure 5, with contributing personnel identified below each box.

Figure 5- GTI CRTMDS Drilling Project Organization

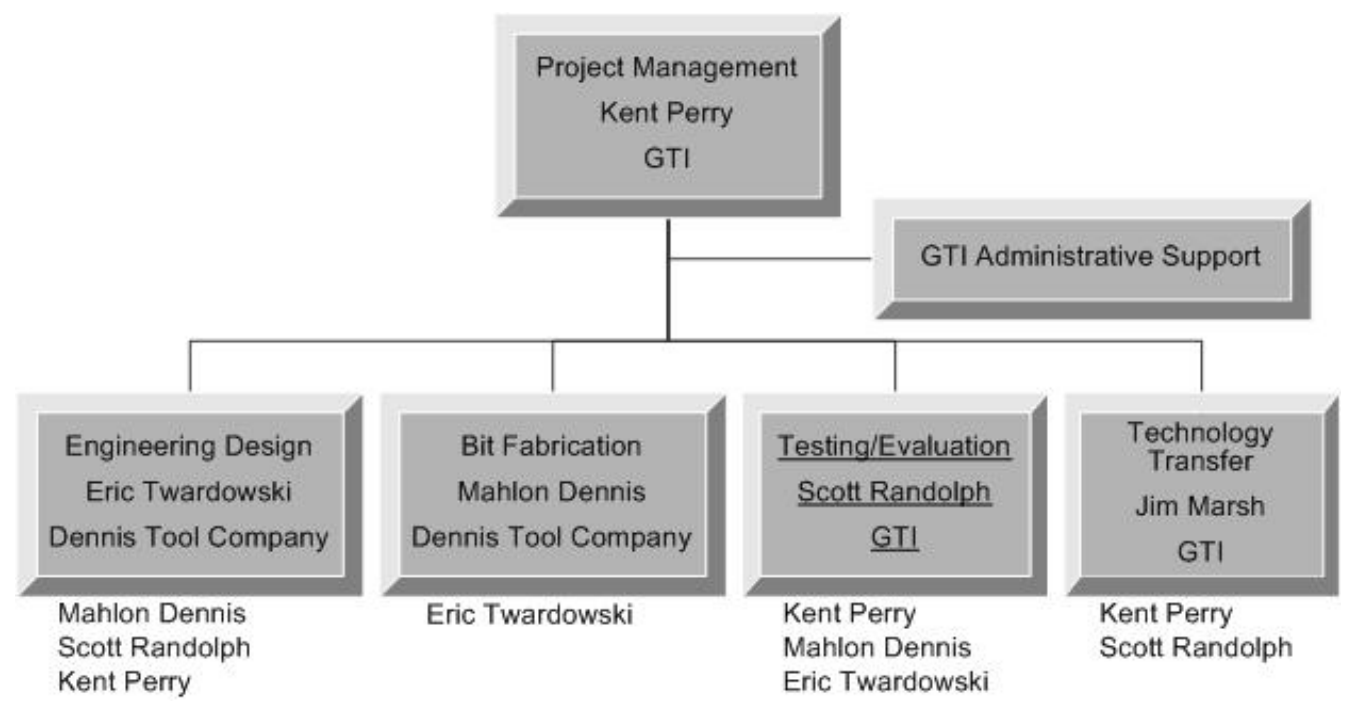

GTI provided project management, collected operational data during field testing, prepared the field test documentation, and managed the technology transfer. Dennis Tool had primary responsibility for the design and fabrication of the bit, as well as has provided maintenance and operations support during the field testing. 


\section{RESULTS AND DISCUSSION OF THE MAJOR TECHNICAL PROBLEMS ENCOUNTERED}

Before any fabrication of the 3-1/2” CRTMDS tool began, a similar dual drilling assembly 2-5/8” tool (See Figure 6) designed for Los Alamos National Laboratories (LANL) was tested in September 2005 at the Rocky Mountain Oilfield Testing Center (RMOTC) near Casper, WY. The smaller 2-5/8 inches tool averaged $82 \mathrm{ft} / \mathrm{hr}$ drilling (130 ft in 1.6 hrs). (See Attachment I for more drilling data details).

Conventional 2-5/8 inches PDC bits average 10-30 ft/hr. As a result of testing the LANL tool, changes to the basic design concept were made to the 3-1 /2"CRTMDS tool to allow diameter ratios among all components to remain the same. Results at RMOTC for the LANL 2 5/8” tool generated some impressive support of the overall tool design. When compared with conventional bits at the same test site, the LANL tool achieved from 4-8 times faster penetration. Although the test only allowed a total of 137 feet to be drilled before a PDM failure, the LANL test proved the design elements of higher rate of penetration using low weight on bit (about 700 pounds) and low reactive torque. The design concept as presented to DOE in this project was proven and was further developed for a proposed 31/2” bit design.

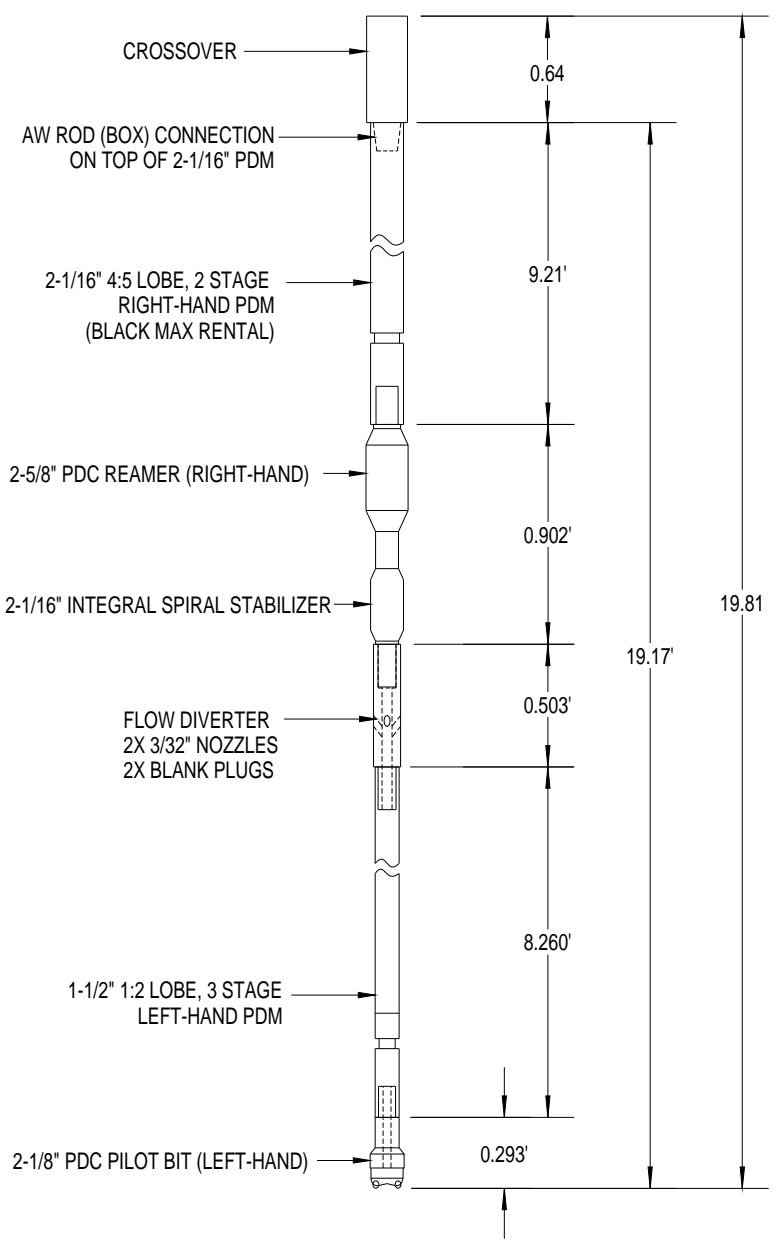

Figure 6 - 2 5/8” CRTMDS 
Due to manufacture delays of the 3-1/2" CRTMDS tool, a planned test at Catoosa's site was rescheduled. In preparation for this upcoming test, a test with the LANL 2-5/8 inches tool was performed on June 6, 2006. The purpose of the test was to allow operators at Catoosa an opportunity to become familiarized with this novel drilling tool, and to test the equipment and procedures in advance of the planned 3-1/2" CRTMDS tests. During the test, it was discovered that the test hole was deviated (Figure 7) and could not be used in its current orientation for an initial CRTMDS test. The hole was plugged and kickoff drilled to allow vertical drilling.

Figure 7 - Hole Condition Prior to Testing

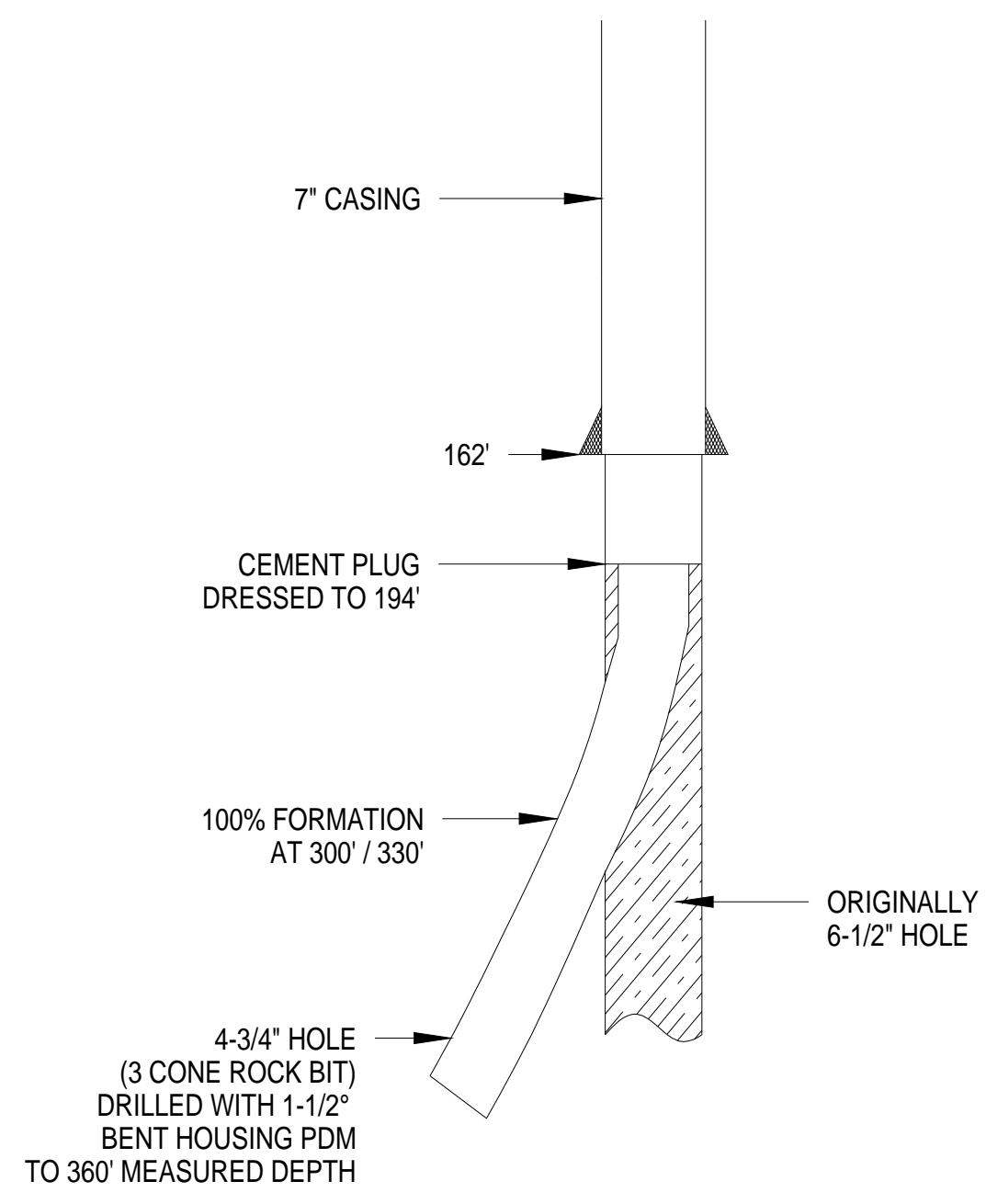


A follow-up test was then performed on June 15, 2006 with the LANL2-5/8 tool at Catoosa's site. The CRTMDS drilled to a depth of 367' with a very low rate of penetration. In an effort to improve the rate of penetration, the flow rate was increased to 23 strokes/min. Soon after increasing the flow rate, the pressure relief on the HT400 mud pump sheared a nail. The nail was replaced and drilling resumed. After a few minutes, the pump sheared another nail. Drilling progressed, but was very slow at 12-20 fph. A larger nail was installed, and drilling resumed. The larger nails did not shear as often as the smaller nails, but the pump did shear at least four of the large nails. At a depth of 375', the rate of penetration was very low. In an attempt to improve the rate of penetration, the flow rate was increased to 28 strokes / min. A change in the drillstring vibration was noticed and very thin black and orange shavings or flakes were found on the flow line returns screen. The CRTMDS drilled to a depth of 382' with a still very low rate of penetration an (average ROP of only $13 \mathrm{fph}$ - 22' drilled in $1.69 \mathrm{hrs}$ ). Based on the unusual vibration, possible rubber in the flow line screen, and low rate of penetration, the bottom hole assembly was pull out of the hole and examined. All components were found to be intact. All PDC cutters were in very good condition with no wear. Some polishing was noted on the outside of the left-hand PDM indicating possible contact with the borehole. In order to isolate the problem, the right-hand PDM was connected to the swivel. When the HT400 pump was engaged, it was clearly notice that the rotation was erratic. The output shaft would spin and then stop repeatedly. Also was noticed that the fluid exiting the PDM was pulsing on and off, good flow followed by little or no flow.The GTI-Catoosa crew disassembled the HT400 pump and discovered broken seal on the center piston valve. Because of the pump situation, no conclusions were drawn in regards to the tool performance from this test.

On March, 2007 the larger 3-1/2” dual drilling assembly tool, referred to as the CRTMDS, was designed and fabricated by Dennis Tool Company. The CRTMDS includes a left-hand turning positive displacement motor (PDM) and left-hand PDC pilot bit in tandem with a right-hand turning PDM and a right-hand PDC reamer with stabilizer. (See Figure 8) 
Figure 8 - BHA of 3-1/2” CRTMDS

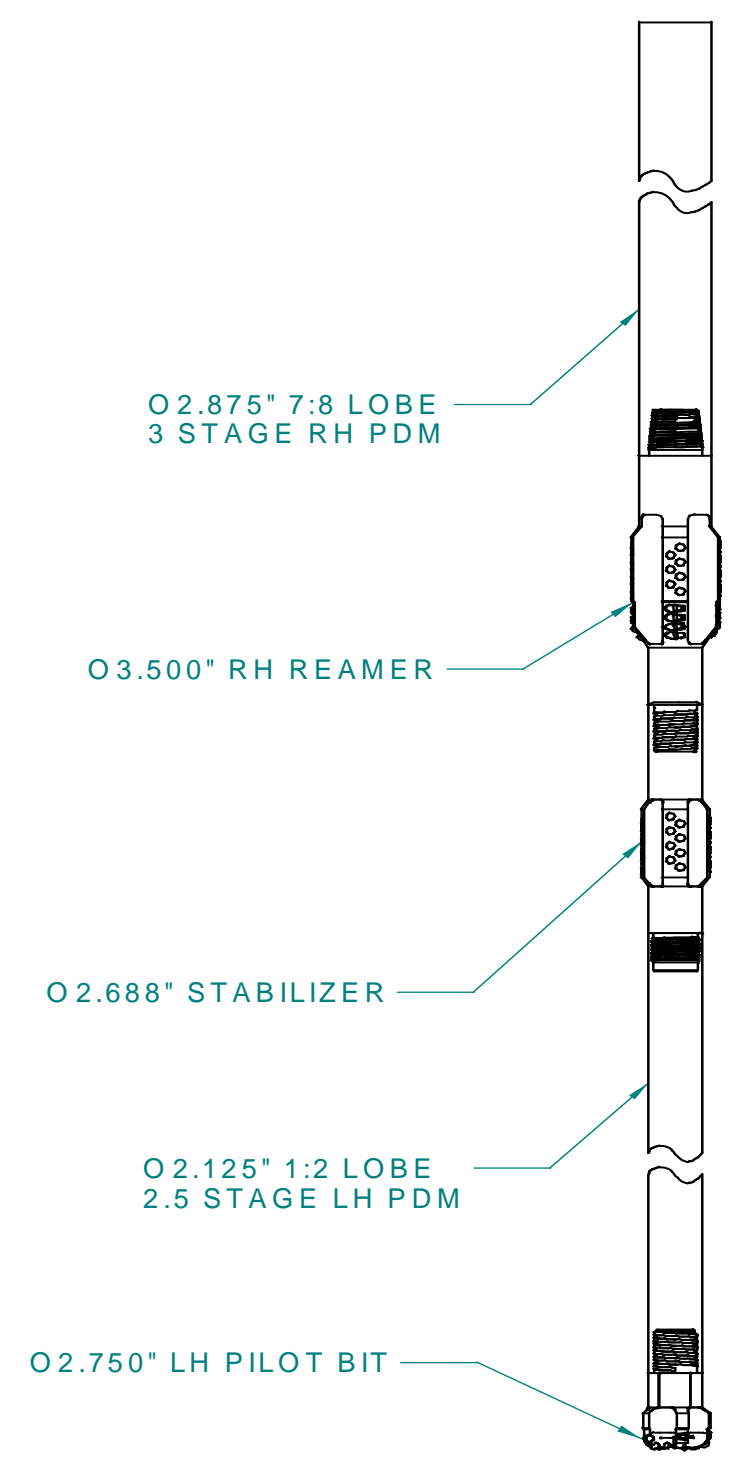

The CRTMDS creates left-hand torque with the pilot bit and right-hand torque with the reamer. Ideally, these torques balance each other for a net of zero reactive torque transmitted to the drillstring. However, since there was a potential that in some instances the left-hand torque will be greater than the right-hand torque and this would create possibly connections back off while drilling; several precautions were taken.

First, all threaded connections within the Bottom hole assembly (BHA) (with the exception of internal components on the right-hand PDM) were secured with Loctite high strength thread-locking compound. Second, where possible, the connections were also welded. The left-hand pilot bit was welded to the output shaft of the left-hand PDM. (See Figure 9) The reamer and stabilizer were also welded together. (See Figure 10) Originally the stabilizer was designed to be integral to the reamer, machined from a solid piece. But, due to size limitations with the milling machine, the reamer and stabilizer were manufactured as two separate pieces. The connection between the reamer and stabilizer was threaded and welded.

Finally, a "starter hole" was drilled 15 feet past the initial TD of the well. The purpose of the "starter hole" was to ensure that the right-hand reamer engages the formation and generates right-hand torque, before the left-hand pilot bit starts to drill. The reamer and pilot bit are about 14 feet apart. For this evaluation, prior to entering the well with the 3-1/2" CRTMDS, a 2-15/16" diameter "starter hole” was drilled with a 
three-bladed tungsten carbide spade bit. This diameter was selected because it is slightly larger than the 2-3/4” pilot bit, and smaller than the 3-1/2” reamer. The 2-15/16” hole was drilled on rotary with an ROP of $30 \mathrm{fph}$.

The following parameters were used: 40 rpm, 65 gpm flow, 400 psi, 1000-2000 lb WOB. The "starter hole" was drilled to a depth of 179 feet (15 feet deeper than the original TD of 164 feet). After drilling the "starter hole” the 3-1/2" CRTMDS was rigged up and run in the hole. The tool started drilling at a depth of 178 feet. Initially, the flow rate was set to 65 gpm, and weight on bit was kept as light as possible. The drillstring rotated at $20 \mathrm{rpm}$. This resulted in a rate of penetration of $28 \mathrm{fph}$ for the first 7 feet drilled. More detailed drilling data can be found in Attachment II and III.

At a depth of 185 feet, the weight on bit was increased to about $1000 \mathrm{lbs}$. The drillstring was not rotated. The rate of penetration increased to about $72 \mathrm{fph}$ in the shale formation (31 feet in 26 minutes).At a depth of 216 feet, the flow rate was increased to 78 gpm. This is about the maximum allowable for the left hand PDM and was also about the maximum flow available with the HT400 pump. Increasing the flow rate dramatically improved the rate of penetration to about $149 \mathrm{fph}$ (72 feet in 29 minutes) while drilling shale. There were several five-foot intervals that drilled at $200 \mathrm{fph}$, but when limestone was encountered at 288 feet the rate of penetration slowed significantly. Weight on bit was increased to 2000 - 2500 lbs. The added weight improved the drilling performance. Limestone, shale, and sandstone were drilled from 288 feet to 342 feet with an average rate of penetration of $51 \mathrm{fph}$ (54 feet in 64 minutes). At this point, the rig was shut down.

The following morning, drilling was resumed. Drilling parameters were $78 \mathrm{gpm}$ flow rate and 2000 to 2500 lbs weight on bit. The first joint of pipe drilled from 342 feet to 374 feet, with an average ROP of 128 fph (32 feet in 15 minutes). Drilling continued at a similar ROP down to a depth of 382 feet. At this point drilling slowed significantly to about 56 fph (20 feet in 21.5 minutes) and at a depth of 402 feet, the CRTMDS stopped drilling altogether. A significant drop ( 500 psi) in the surface pressure was noted. This pressure drop indicated than part of the BHA may have backed-off downhole.

The tool was pulled out of the hole. The drillpipe, right-hand PDM, and PDC reamer were retrieved. The stabilizer, left-hand PDM, and left-hand pilot bit were still in 
the hole. The connection between the reamer and stabilizer were backed-off. This particular connection had been welded together, but the weld cracked.

The objective of this test was to demonstrate the drilling performance of the 3$1 / 2$ " tool. The test proved that the counter-rotating tandem motor system can effectively drill with a high rate of penetration and low weight on bit. A total of 224 feet of shale, limestone, and sandstone were drilled in 3 hours (75 fph overall average). The rate of penetration reached $200 \mathrm{fph}$ in some shale intervals. But a better method for limiting lefthand torque, limiting vibration, and securing downhole connections was needed.

\section{Figure 9- Pilot Bit}

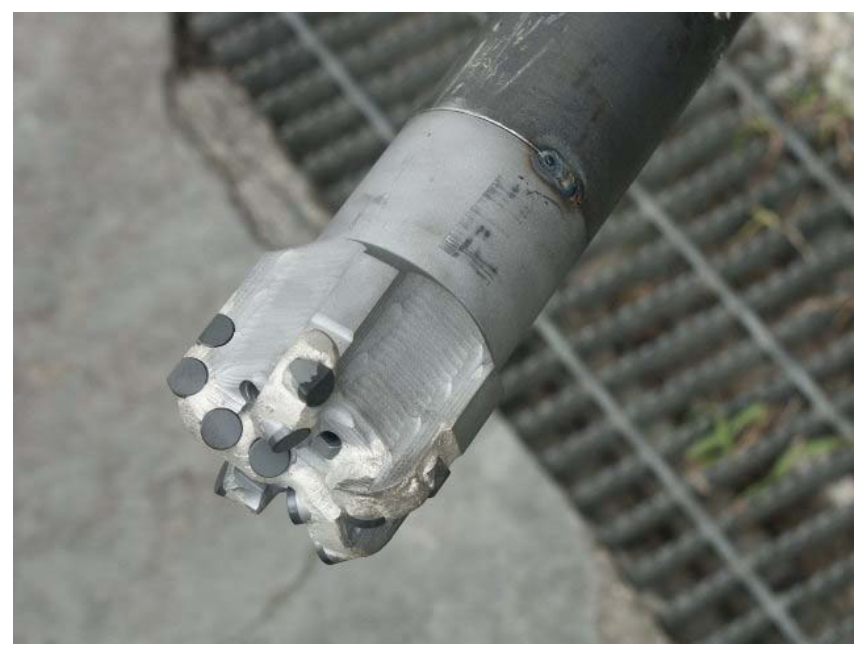

\section{Figure 10- Reamer and Stabilizer}

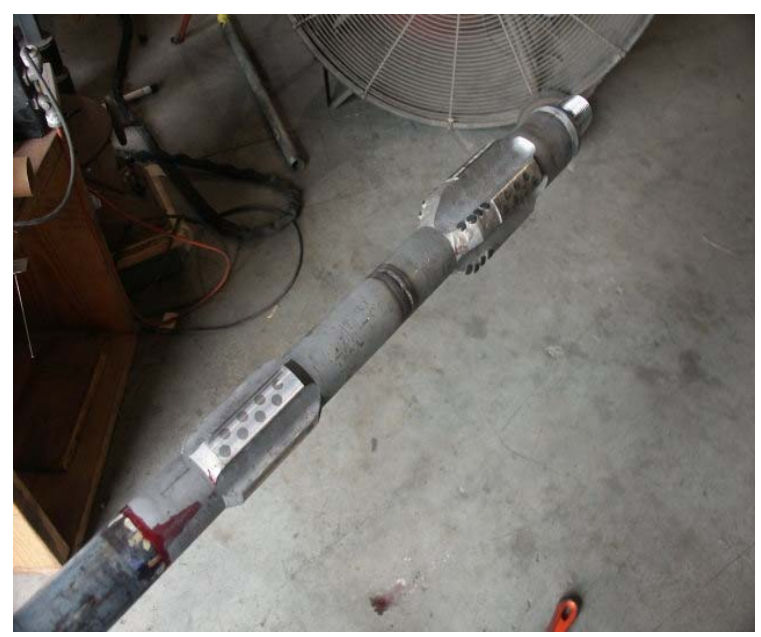

In July, 2008 a detailed design for a CRTMDS was developed and the tool fabricated. This design was based similar to the design tested for Los Alamos National Laboratory (LANL) in September 2005 at the Rocky Mountain Oilfield Testing Center near Casper, WY. The smaller, 2-5/8-inches tool averaged 82 feet/hour drilling (130 feet in 1.6 hours). Conventional 2-5/8-inches polycrystalline diamond compact bits average 10-30 feet/hour. Several tests performed at GTI's Catoosa test site showed that although high penetration rates were easily achieved, the tool twisted off between the two counter rotating cutter systems. Based on these observations, a new design was prepared.

The new design has a motor that develops significant torque in a short length and does not contain the typical failure prone rubber or urethane stator components. A single, left hand vane motor, left hand bit, and proper pin connections were assembled as soon as 
possible to perform a test run at the GTI Catoosa test facility. All bearings and major wear components within the new motor were upgraded to Polycrystalline Diamond Compact Bits (PDC), yielding an order of magnitude greater wear resistance and reliability.

The fabrication of the new design was completed. A brief description of the new design follows. The new design is for a slim motor with a 2-1/8" OD to be used on a 23/4" drillstring and with 2-7/8" drill bit (Figure 11). The motor required very tight tolerance and precision machining. After several minor modifications, the motor was tested in Dennis Tool's shop successfully.

\section{Figure 11 - Bottom hole Assembly for slim motor (Micromotor)}

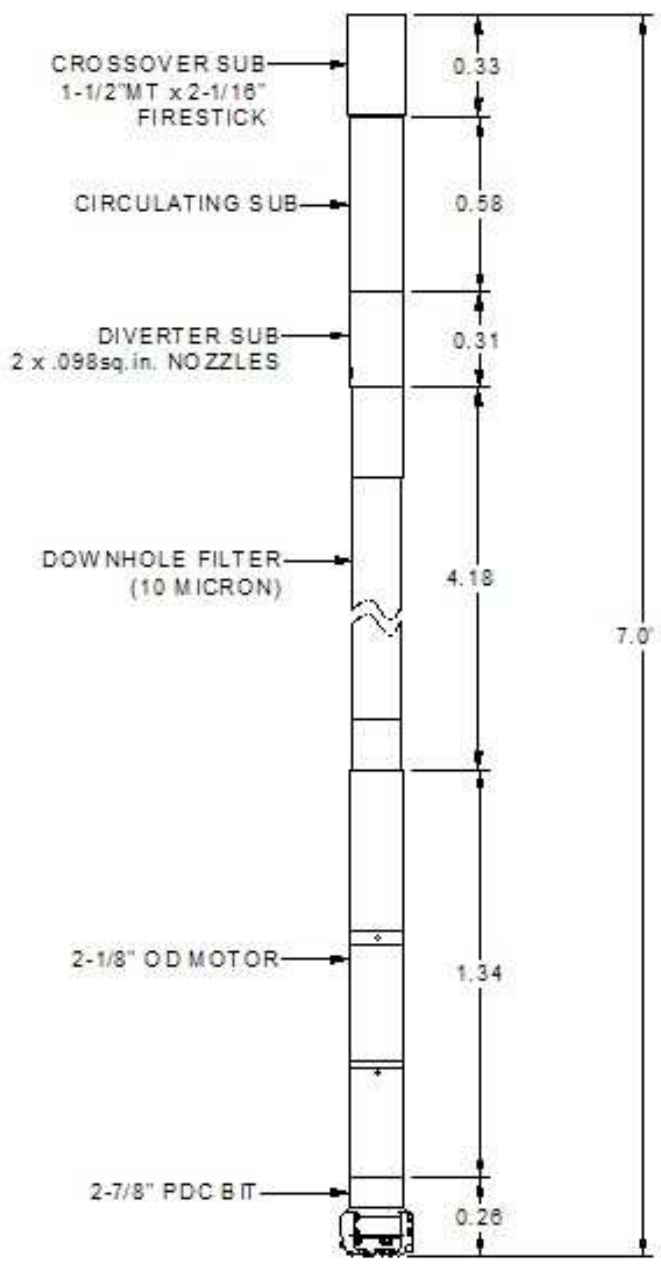


On March 16, 2009 the tool was tested at GTI Catoosa site. The test revealed that because of the tight tolerance, solid particles in conventional drilling fluids caused jamming of the motor. To overcome this problem, a 10 micron filter was added to the string and test repeated. Results from this modification were also negative.

\section{CONCLUSION}

Several variations of the CRTDMS were designed, manufactured and tested. The original tests failed leading to design modifications. Two versions of modified system were tested and showed that the concept is both positive and practical and has a very high potential of reducing the drilling costs of slim holes; however, the tests showed that for the system to be robust and durable, borehole diameter should be substantially larger than that of slim holes. As a result, the research team decided to complete the project, document the tested designs and seek further support for the concept outside of the DOE. 


\section{ATTACHMENT I}

DENNIS TOOL COMPANY - LANL 2.625" CRTMDS TOOL 09/01/2005

RMOTC CASPER, WY

\begin{tabular}{|c|c|c|c|c|c|c|c|c|}
\hline TIME & DEPTH (FT) & WOB (LBS.) & $\begin{array}{l}\text { FLOW RATE } \\
\text { (GPM) }\end{array}$ & $\begin{array}{c}\text { SUFACE } \\
\text { PRESSURE (PSI) }\end{array}$ & $\begin{array}{l}\text { ELAPSED } \\
\text { TIME (HRS) }\end{array}$ & $\begin{array}{c}\text { DEPTH } \\
\text { DRILLED (FT) }\end{array}$ & $\begin{array}{c}\text { AVERAGE } \\
\text { FROM START } \\
\text { ROP (FPH) }\end{array}$ & $\begin{array}{c}\text { OVER } \\
\text { INTERVAL } \\
\text { ROP (FPH) }\end{array}$ \\
\hline $9: 30$ & 50.0 & 700 & 35 & 3050 & 0.00 & 0.0 & & \\
\hline $9: 42$ & 63.8 & 700 & 35 & 3050 & 0.20 & 13.8 & 69.0 & 69.0 \\
\hline $9: 45$ & 70.5 & 700 & 35 & 3050 & 0.25 & 20.5 & 82.0 & 134.0 \\
\hline $9: 53$ & 81.9 & 700 & 36 & 3050 & 0.38 & 31.9 & 83.2 & 98.7 \\
\hline $10: 00$ & 93.0 & 700 & 36 & 3050 & 0.50 & 43.0 & 86.0 & 95.1 \\
\hline $10: 04$ & 101.5 & 700 & 40 & 3450 & 0.57 & 51.5 & 90.9 & 127.5 \\
\hline $10: 10$ & 110.5 & 700 & 40 & 3500 & 0.67 & 60.5 & 90.8 & 90.0 \\
\hline $10: 20$ & 124.5 & 700 & 39 & 3450 & 0.83 & 74.5 & 89.4 & 84.0 \\
\hline $10: 30$ & 137.7 & 700 & 40 & 3400 & 1.00 & 87.7 & 87.7 & 79.2 \\
\hline $10: 40$ & 147.8 & 700 & 39 & 3400 & 1.17 & 97.8 & 83.8 & 60.6 \\
\hline $10: 45$ & 153.5 & 700 & 39 & 3300 & 1.25 & 103.5 & 82.8 & 68.4 \\
\hline $10: 50$ & 158.6 & 700 & 39 & 3400 & 1.33 & 108.6 & 81.5 & 61.2 \\
\hline $11: 00$ & 173.4 & 700 & 39 & 3400 & 1.50 & 123.4 & 82.3 & 88.8 \\
\hline $11: 05$ & 180.0 & 700 & 39 & 3400 & 1.58 & 130.0 & 82.1 & 79.2 \\
\hline
\end{tabular}

INTERVAL ROP

Dennis Tool 2-5/8" CRTMDS Test at RMOTC 09-01-05

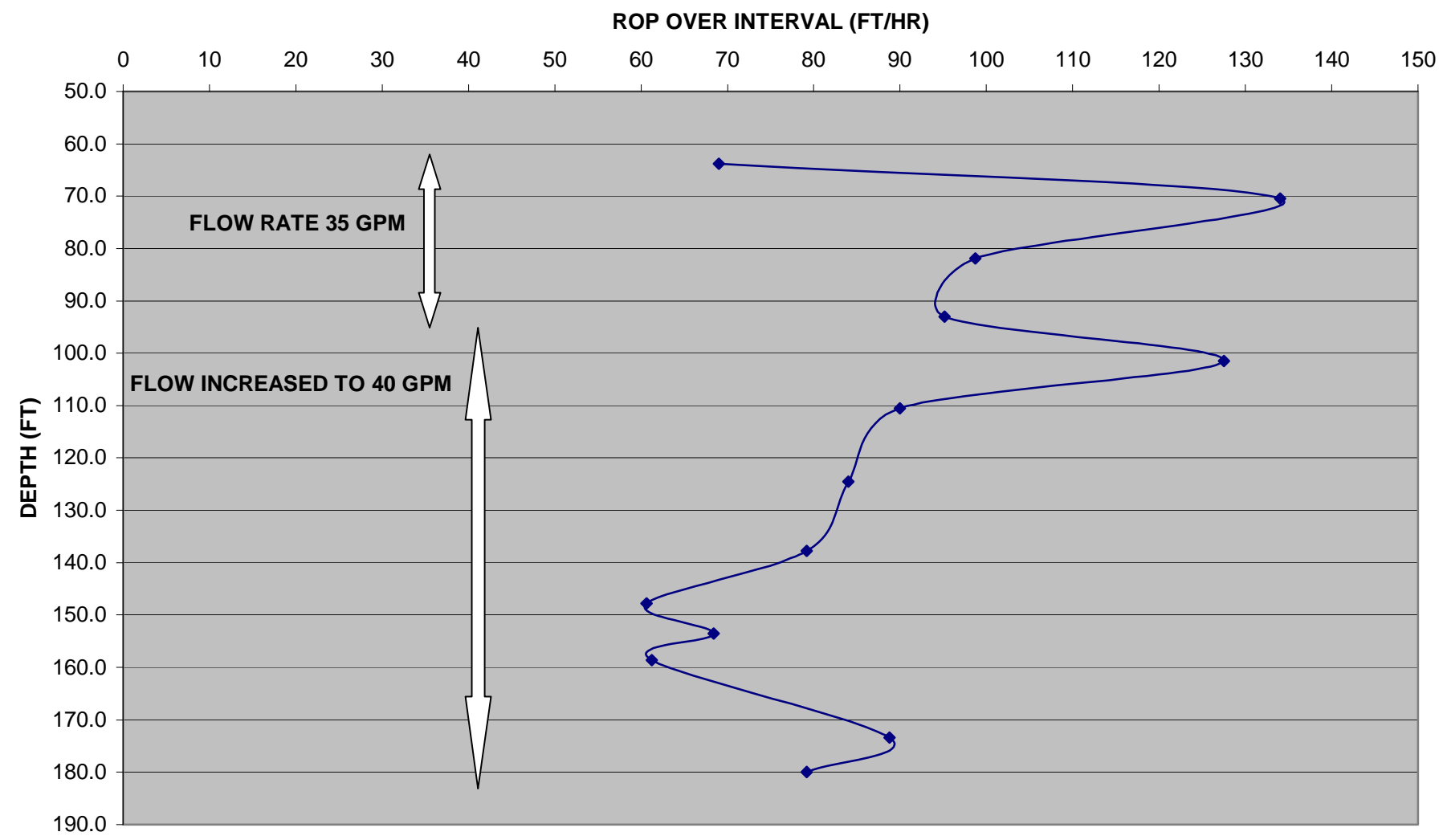




\section{ATTACHMENT II}

\begin{tabular}{|c|c|c|c|c|c|c|c|}
\hline \multicolumn{8}{|c|}{ 3-1/2" CRTMDS } \\
\hline DATE: & 27-Mar-07 & & & & & & \\
\hline LOCATION: & GTI-CATOOSA & & & & & & \\
\hline \multirow{4}{*}{ BHA: } & \multicolumn{7}{|c|}{ 2.750" PILOT BIT (LH); 2.125" 1:2 2.5 STAGE LH PDM; 2.688" STABILIZER; 3.500" REAMER (RH); 2.875" 7:8 3 STAGE PDM (RH) } \\
\hline & \multicolumn{6}{|c|}{ XO TO TOP MOTOR IS WELDED TO A DAMAGED JOINT OF PIPE (NOT INCLUDED IN BHA LENGTH) } & \\
\hline & BHA LENGTH $=2$ & $26.52^{\prime}$ & & & & & \\
\hline & TD START $=1$ & & & & & & \\
\hline DEPTH (FT) & TIME OF DAY & DELTA (MIN) & ROP (FPH) & FLOW RATE (GPM) & PUMP PSI & WOB (LBS.) & TORQUE (FT-LB) \\
\hline 178 & $14: 25$ & & & 65 & $900-1100$ & 1000 & 260 \\
\hline 183 & $14: 35$ & 10.00 & 30.0 & 65 & $900-1100$ & 1000 & 50 \\
\hline 185 & $14: 40$ & 5.00 & 24.0 & 65 & $900-1100$ & 1000 & 50 \\
\hline MAKE CONN & IECTION & & & & & & \\
\hline 185 & $14: 53$ & & & 65 & $900-1100$ & 1000 & 10 \\
\hline 189 & $14: 58$ & 5.00 & 48.0 & 65 & $900-1100$ & 1000 & 10 \\
\hline 190 & $14: 59$ & 1.00 & 60.0 & 65 & $900-1100$ & 1000 & 10 \\
\hline 195 & $15: 03$ & 4.00 & 75.0 & 65 & $900-1100$ & 1000 & 10 \\
\hline 200 & 15:06 & 2.75 & 109.1 & 65 & $900-1100$ & 1000 & 10 \\
\hline 205 & $15: 10$ & 4.00 & 75.0 & 65 & $900-1100$ & 1000 & 10 \\
\hline 210 & $15: 14$ & 3.66 & 82.0 & 65 & $900-1100$ & 1000 & 10 \\
\hline 215 & $15: 18$ & 3.83 & 78.3 & 65 & $900-1100$ & 1000 & 10 \\
\hline 216 & 15:19 & 0.83 & 72.3 & 65 & $900-1100$ & 1000 & 10 \\
\hline MAKE CONN & IECTION & & & & & & \\
\hline 216 & $15: 45$ & & & 78 & $1200-1400$ & 1000 & -50 \\
\hline 221 & $15: 47$ & 2.25 & 133.3 & 78 & $1200-1400$ & 1000 & -50 \\
\hline 226 & $15: 48$ & 1.58 & 189.9 & 78 & $1200-1400$ & 1000 & -50 \\
\hline REPAIR LEAL & K3 MINUTES & & & & & & \\
\hline 227 & $15: 51$ & & & 78 & $1200-1400$ & 1000 & -50 \\
\hline 231 & $15: 53$ & 1.50 & 160.0 & 78 & $1200-1400$ & 1000 & -50 \\
\hline 236 & $15: 55$ & 1.83 & 163.9 & 78 & $1200-1400$ & 1000 & -50 \\
\hline 241 & $15: 57$ & 1.92 & 156.3 & 78 & $1200-1400$ & 1000 & -50 \\
\hline 246 & $15: 59$ & 2.75 & 109.1 & 78 & $1200-1400$ & 1000 & -50 \\
\hline 248 & 16:00 & 0.67 & 179.1 & 78 & $1200-1400$ & 1000 & -50 \\
\hline MAKE CONN & IECTION & & & & & & \\
\hline 248 & 16:12 & & & 78 & $1200-1400$ & 1000 & -50 \\
\hline 253 & 16:15 & 2.42 & 124.0 & 78 & $1200-1400$ & 1000 & -50 \\
\hline 258 & $16: 17$ & 1.83 & 163.9 & 78 & $1200-1400$ & 1000 & -50 \\
\hline 263 & $16: 18$ & 1.33 & 225.6 & 78 & $1200-1400$ & 1000 & -50 \\
\hline 268 & 16:19 & 1.53 & 196.1 & 78 & $1200-1400$ & 1000 & -60 \\
\hline 273 & $16: 22$ & 2.58 & 116.3 & 78 & $1200-1400$ & 1000 & -60 \\
\hline 278 & $16: 25$ & 2.00 & 150.0 & 78 & $1200-1400$ & 1000 & -60 \\
\hline 279 & $16: 25$ & 0.50 & 120.0 & 78 & $1200-1400$ & 1000 & -60 \\
\hline MAKE CONN & IECTION & & & & & & \\
\hline 279 & $16: 37$ & & & 78 & $1200-1400$ & 1000 & -60 \\
\hline 284 & $16: 39$ & 1.87 & 160.4 & 78 & $1200-1400$ & 1000 & -60 \\
\hline 287 & $16: 41$ & 1.66 & 108.4 & 78 & $1200-1400$ & 1000 & -60 \\
\hline 288 & $16: 43$ & 1.00 & 60.0 & 78 & $1200-1400$ & 1000 & -60 \\
\hline 289 & 16:43 & 1.00 & 60.0 & 78 & $1200-1400$ & 1000 & -60 \\
\hline 290 & $16: 44$ & 1.00 & 60.0 & 78 & $1200-1400$ & 1000 & -60 \\
\hline 294 & $16: 48$ & 4.33 & 55.4 & 78 & $1200-1400$ & 1000 & -60 \\
\hline 299 & $16: 55$ & 6.50 & 46.2 & 78 & $1200-1400$ & 1000 & -60 \\
\hline 304 & $17: 04$ & 9.00 & 33.3 & 78 & $1200-1400$ & 2000 & -50 \\
\hline 309 & $17: 14$ & 10.00 & 30.0 & 78 & $1200-1400$ & 2000 & -50 \\
\hline 311 & $17: 15$ & 1.80 & 66.7 & 78 & $1200-1400$ & 2000 & -50 \\
\hline MAKE CONN & IECTION & & & & & & \\
\hline 311 & $17: 40$ & & & 78 & $1200-1400$ & 2000 & -20 \\
\hline 316 & $17: 46$ & 6.25 & 48.0 & 78 & $1200-1400$ & 2000 & -20 \\
\hline 321 & $17: 53$ & 6.83 & 43.9 & 78 & $1200-1400$ & 2000 & -30 \\
\hline 326 & $17: 57$ & 4.25 & 70.6 & 78 & $1200-1400$ & 2000 & -30 \\
\hline 331 & 18:02 & 4.33 & 69.3 & 78 & $1200-1400$ & 2000 & -30 \\
\hline 336 & 18:08 & 6.28 & 47.8 & 78 & $1200-1400$ & 2000 & -30 \\
\hline 341 & 18:11 & 3.10 & 96.8 & 78 & $1200-1400$ & 2000 & -30 \\
\hline 342 & 18:12 & 0.67 & 89.6 & 78 & $1200-1400$ & 2000 & -30 \\
\hline MAKE CONN & IECTION AND ST & TOP FOR NIGH & & & & & \\
\hline 342 & $7: 52$ & & & 78 & $1200-1400$ & 2000 & -30 \\
\hline 347 & $7: 56$ & 4.00 & 75.0 & 78 & $1200-1400$ & 2000 & -30 \\
\hline 352 & $7: 58$ & 1.67 & 179.6 & 78 & $1200-1400$ & 2000 & -30 \\
\hline 357 & $7: 59$ & 1.75 & 171.4 & 78 & $1200-1400$ & 2000 & -30 \\
\hline 362 & $8: 01$ & 1.75 & 171.4 & 78 & $1200-1400$ & 2000 & -30 \\
\hline 367 & $8: 03$ & 2.00 & 150.0 & 78 & $1200-1400$ & 2000 & -30 \\
\hline 372 & $8: 05$ & 2.50 & 120.0 & 78 & $1200-1400$ & 2000 & -30 \\
\hline 374 & $8: 07$ & 0.80 & 150.0 & 78 & $1200-1400$ & 2000 & -30 \\
\hline MAKE CONN & IECTION & & & & & & \\
\hline 374 & $8: 16$ & & & 78 & $1300-1500$ & 2000 & -30 \\
\hline 379 & 8:19 & 3.00 & 100.0 & 78 & $1300-1500$ & 2000 & -30 \\
\hline 382 & $8: 20$ & 1.50 & 120.0 & 78 & $1300-1500$ & 2000 & -40 \\
\hline 384 & $8: 24$ & 4.00 & 30.0 & 78 & $1300-1500$ & 2000 & -40 \\
\hline 389 & $8: 31$ & 7.00 & 42.9 & 78 & $1300-1500$ & 2000 & -50 \\
\hline 394 & $8: 37$ & 6.00 & 50.0 & 78 & $1300-1500$ & 2000 & -50 \\
\hline 399 & $8: 43$ & 5.50 & 54.5 & 78 & $1300-1500$ & 2000 & -40 \\
\hline 402 & $8: 46$ & 3.00 & 60.0 & 78 & $1300-1500$ & 2000 & -40 \\
\hline
\end{tabular}


ATTACHMENT III

\section{ROP DATA - 3.500" CRTMDS \\ CATOOSA MARCH 2007}

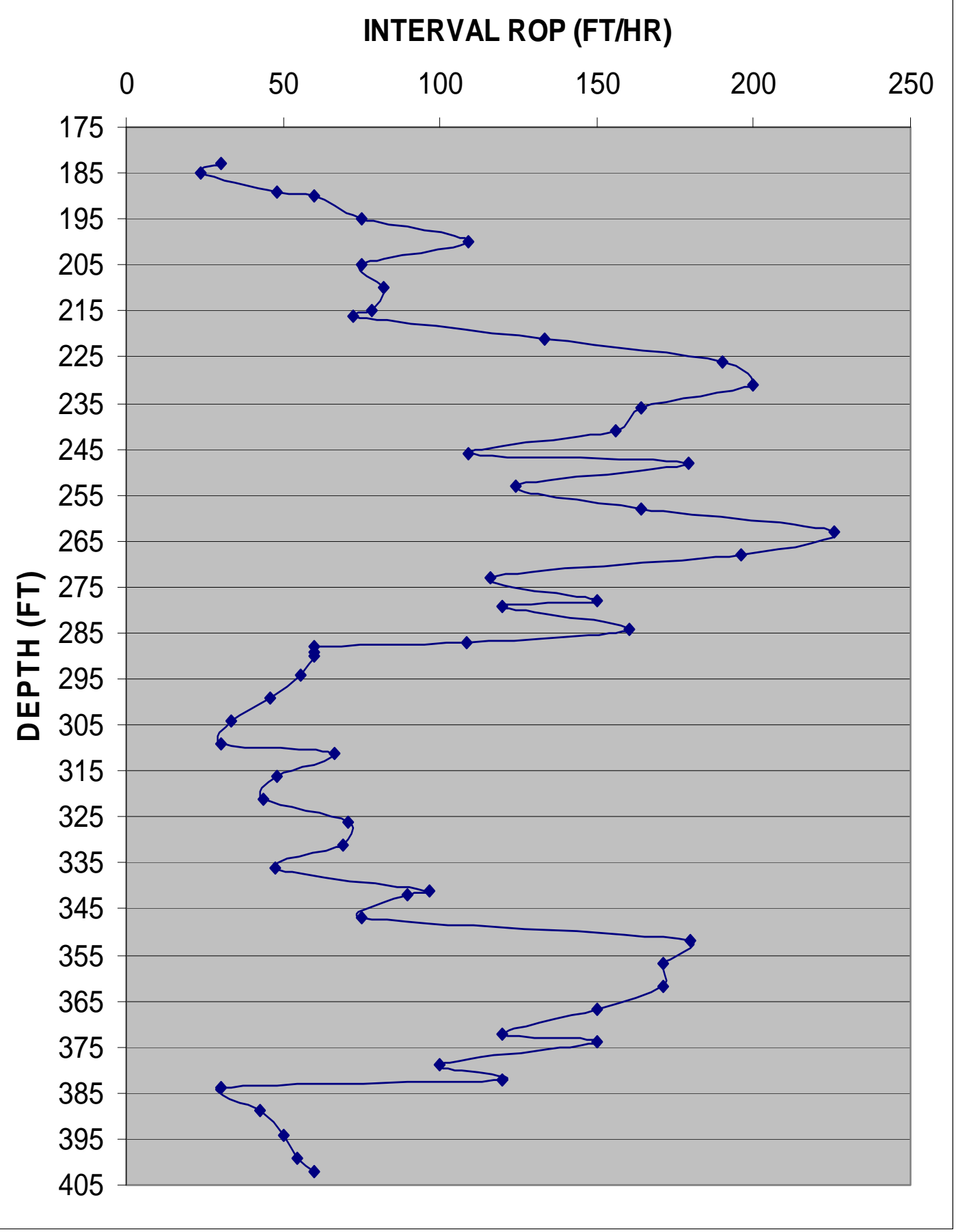




\title{
ATTACHMENT IV
}

\author{
Field Test Evaluation Report \\ Los Alamos National Laboratory (LANL) \\ 2-5/8” CRTMDS TOOL AT RMOTC
}

September 01, 2005

Prepared by:

Eric Twardowski

Dennis Tool Company

Houston, TX 


\section{Objective:}

To evaluate the drilling performance of a Counter-Rotating Tandem Motor Drilling System (CRTMDS) for use by the Los Alamos National Laboratory (LANL) during the microhole field test at the Rocky Mountain Oilfield Testing Center (RMOTC) near Casper, Wyoming.

\section{Background:}

A dual drilling assembly, referred to as the CRTMDS, has been designed and fabricated by Dennis Tool Company for use in the LANL microhole field test. The CRTMDS includes a left-hand turning positive displacement motor (PDM) and left-hand PDC pilot bit in tandem with a right-hand turning PDM and a right-hand PDC reamer with integral spiral stabilizer (see attached drawing of bottom hole assembly (BHA), Figure A-1).

The performance of the new tool was demonstrated during a field test at RMOTC on September 01, 2005. It was anticipated that the dual, counter-rotating cutting assembly should result in a high drilling rate of penetration (ROP) with low weight on bit (WOB), in addition to a reduction in the net reactive torque transmitted to the coiled tubing. This should complement the limited capabilities available with the LANL microhole coiled tubing drilling unit.

The CRTMDS assembly follows DOE work in the original tandem motor project (both motors turning in a right-hand direction) evaluated at RMOTC in October 2004.

\section{RMOTC location information:}

Test date: $\quad$ September 01, 2005

Lease: $\quad$ Naval Petroleum Reserve \#3

Operator: Department of Energy

Contractor: Los Alamos National Laboratory

Field: $\quad$ Teapot Dome 
Well name: 34-1-X-34 MH3

Elevation: $\quad 5176 \mathrm{GL}$

Location: SWNE Qtr ne/4,sw/4,se/4

Section: $\quad 3$

Township: T-38-N

Range: $\quad$ R-78-W

County: Natrona

State: Wyoming

\section{Equipment information:}

Rig: $\quad$ LANL CTU \#1 with1650 feet of 1” OD coiled tubing ( 0.81 ” ID)

Supervisor: Jim Thomson

Pump: $\quad$ Gardner-Denver PAH 200 rated at 5000 psi. 4.5” liner

A manual choke was installed in the flow line to regulate flow into the CT unit.

PDM's: $\quad$ Right-hand 2-1/16”, 4:5 lobe, 2 stage (rental from BlackMax)

Left-hand 1-1/2", 1:2 lobe, 3 stage (purchased from Grifco)

Pilot bit: $\quad$ Dennis Tool Company, Left-hand 2-1/8” PDC bit. 5 blades, 7 face cutters ( 0.375 ” diameter) at $25^{\circ}$ backrake

Reamer: $\quad$ Dennis Tool Company, Right-hand 2-5/8” PDC reamer with integral 2-1/16” spiral stabilizer. 4 blades, 8 face cutters $(0.375$ ” diameter) at $25^{\circ}$ backrake

Flow diverter: To dump excess flow from right-hand PDM before entering lefthand PDM.

Two 3/32" nozzles, Two blank plugs.

Drilling fluid: Water with KCL, 8.3 ppg

Formation: Shale

\section{BHA:}

CTU connection; 2-1/2" stabilizer; 2-1/16" 4:5 lobe 2 stage right-hand PDM; 25/8" reamer with integral 2-1/16" stabilizer; flow diverter with two 3/32"nozzles 
and two blank plugs; 1-1/2” 1:2 lobe 3 stage left-hand PDM; 2-1/8” left-hand pilot bit. (Overall length of BHA = 20.19 feet)

(see photos Appendix A-1)

\section{Test summary:}

Prior to connecting the BHA, a flow test was conducted to determine the pressure drop through the coiled tubing at various flow rates, ranging from 10 to 50 gpm. (see Figure A-2)

A foam pig had been previously set at the bottom of the conductor pipe. Jim Thomson recommended that the pig be drilled out before running in the hole with the CRTMDS. LANL opted to drill out the foam pig using a 2-3/8”, 3 blade carbide chevron bit driven by the 2-1/16” right-hand PDM rented from BlackMax for the CRTMDS test. This PDM did not function properly. It was returned to BlackMax in Casper for repair. An assembly problem was discovered in the bearing section. This section was replaced. The following day, an attempt was made to drill out the foam pig. This time, the BlackMax motor functioned properly. However, the bit was not able to drill out the foam pig. It is likely that the pig was simply pushed to the side of the hole, and the bit was able to drill past it. This BHA was then pulled out of the hole at 8:30am.

The CRTMDS was then assembled. Loc-Tite thread lock was used to secure the pilot bit to the left-hand PDM. According to Grifco, all internal threaded connections on the 11/2” left-hand PDM were also secured with thread lock.

The CRTMDS was run in the hole at 9:30 am. Initially, the flow rate was set at $35 \mathrm{gpm}$, resulting in a surface pressure of 3050-3100 psi. At this flow rate, the CRTMDS drilled from 50' to 93' in 0.5 hours (86 fph average at $35 \mathrm{gpm}$ ). There was no precise way to measure WOB, but based on hydraulic pressure supplied to the injector on the CT unit, the WOB was estimated to be 600-900 lbs. 
In an effort to improve ROP, the flow rate was then increased to $40 \mathrm{gpm}$, resulting in a surface pressure of about 3450 psi. WOB was estimated to still be approximately 600900 lbs. Drilling continued to a depth of 180', a further 87' in 1.08 hours (80.5 fph average at $40 \mathrm{gpm}$ ). (See Table A-2 for specific drilling data points.)

At a depth of 180' drilling progress stopped. A 200 psi decrease in surface pressure was noted. After a brief attempt to drill ahead with no progress, the BHA was pulled out of the hole.

It was discovered that the top sub on the 1-1/2" left-hand PDM had backed off of the stator housing. This was a right-hand thread connection. The 1-1/2” PDM and 2-1/8” pilot bit were left in the hole. The remainder of the BHA was laid down at 11:25 am.

The CT unit was moved out of the way and a RMOTC pulling unit was moved over the hole. An overshot was then run in on sucker rod. While pulling out of the hole on the first fishing attempt, one of the rod couplings hung the foam pig and pulled it up into the wellbore. The fish was not retrieved on this attempt. On the second fishing attempt, the foam pig prevented the overshot from getting downhole. A spear was then run on the sucker rod, and the foam pig was successfully retrieved from the hole. The 1-1/2” PDM and pilot bit were finally retrieved after two additional fishing attempts (5:00 pm).

The threaded connection between the top sub and stator on the 1-1/2" PDM was examined. The threads were worn (see photo in Figure A-5). It is likely that this wear took place after the connection backed off, and could have been caused during the brief attempt to drill ahead after drilling progress halted at 180'. There was no visible evidence of thread lock on this connection. However, it could have been washed away or rubbed off during the attempt to drill ahead. The manufacturer of the 1-1/2” PDM says that the connection did have thread lock.

There was no other obvious damage to the CRTMDS. The pilot bit and reamer were in excellent condition, with no signs of wear on the cutting structure. 
The CRTMDS drilled 130' in 1.58 hours, for an average ROP of 82 fph. Jim Thomson indicated that this was significantly faster than they had previously been able to drill a 25/8” hole size. Using conventional PDC bits and conventional motors, they typically drilled with an ROP in the 10-30 fph range, as compared to the ROP of $82 \mathrm{fph}$ achieved with the CRTMDS. The CRTMDS performed very well before the connection backed off.

\section{Plans for future testing:}

The CRTMDS will be shipped back to Dennis Tool for evaluation. The 1-1/2” left hand PDM will then be returned to the manufacturer in order to determine why the top sub backed off from the stator. The PDM will also be disassembled and inspected for signs of wear. Potential solutions to prevent threaded connections from backing off will be discussed, and an attempt will be made to correct the problem.

Jim Thomson indicated that they are trying to obtain a drilling permit for another well at RMOTC. It is possible that they may drill another well in October 2005. Dennis Tool hopes to have a solution to the thread connection problem by that time. If LANL is willing to provide another test opportunity, Dennis Tool would like to run the CRTMDS again, in hopes of acquiring more data on the performance and longevity of the tool. Based on the high ROP achieved with the CRTMDS, a subsequent evaluation would be beneficial to both LANL and Dennis Tool Company. 


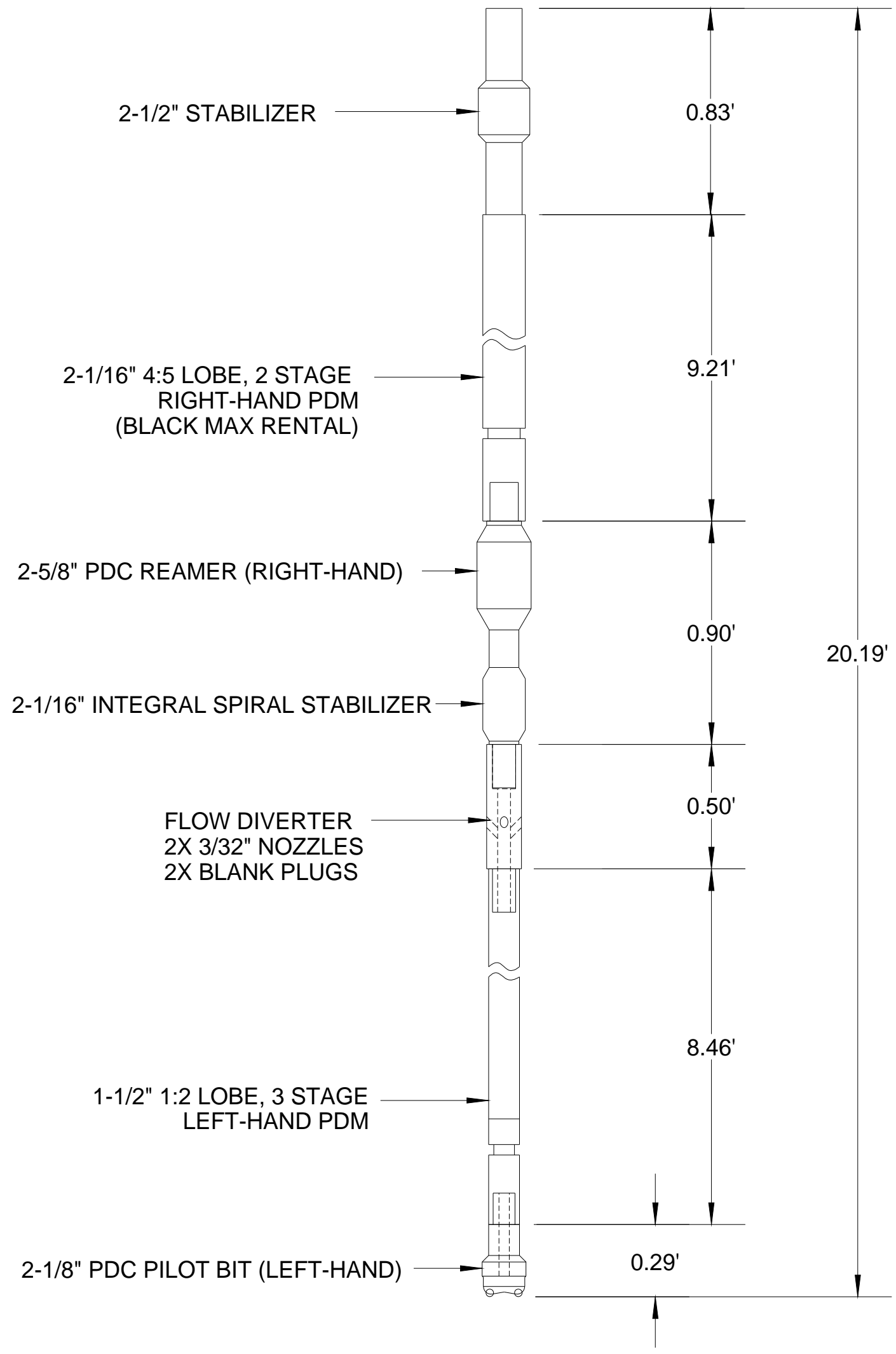

Figure A-1 - Bottom Hole Assembly (CRTMDS) 


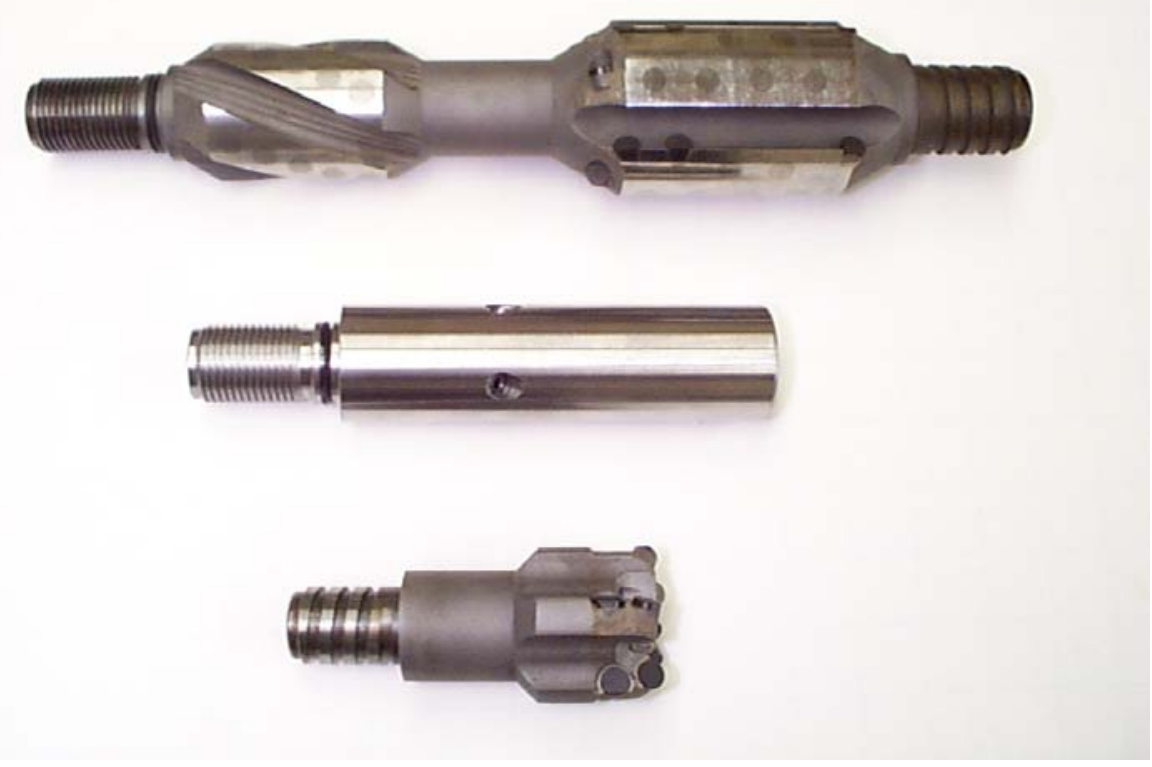

Reamer / stabilizer (top), Flow diverter (middle), Pilot bit (bottom)

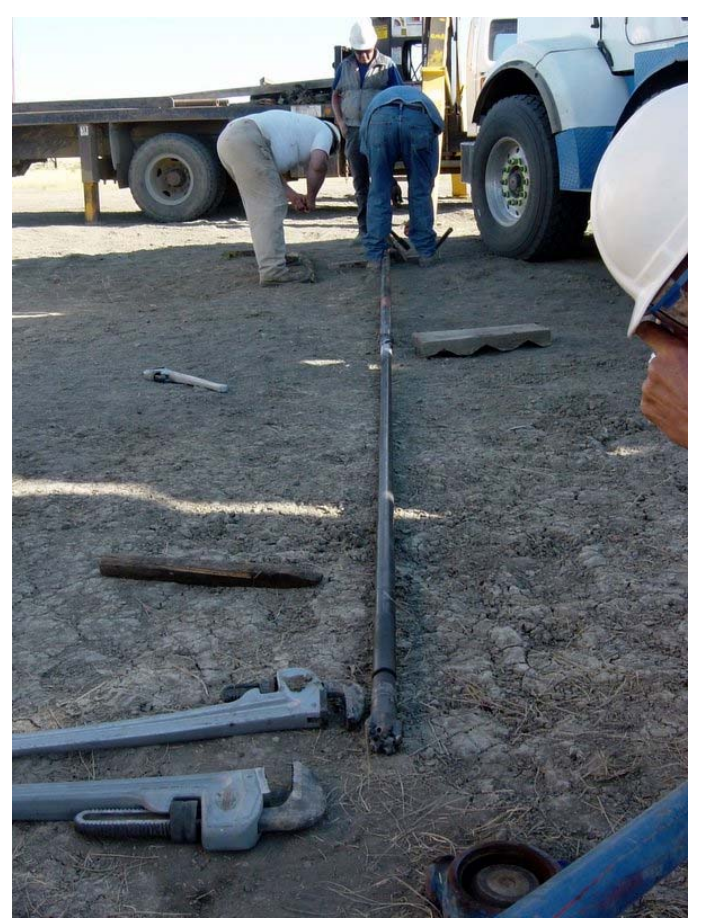

BHA assembly at RMOTC

Figure A-2 - Photos of BHA 
Table A-1 - Pressure Drop vs. Flow Rate

LANL CTU\#1, 1650' of 1" OD (0.81” ID) Coiled Tubing

Tubing only (no BHA), water with KCL 8.2 ppg

$\begin{array}{cc}\begin{array}{c}\text { FLOW RATE } \\ \text { (gpm) }\end{array} & \begin{array}{c}\text { PRESSURE DROP } \\ \text { (psi) }\end{array} \\ 10.5 & 450 \\ 12.4 & 500 \\ 14.0 & 600 \\ 15.0 & 650 \\ 17.0 & 700 \\ 18.0 & 750 \\ 19.5 & \mathbf{8 5 0} \\ 20.0 & 900 \\ 24.5 & 1150 \\ 25.2 & 1200 \\ 29.0 & 1500 \\ 30.0 & 1600 \\ 35.0 & 2000 \\ 38.0 & 2250 \\ 39.7 & 2500 \\ 43.7 & 3000 \\ 45.0 & 3100 \\ 46.5 & 3350 \\ 48.5 & 3500 \\ 49.5 & 3650\end{array}$

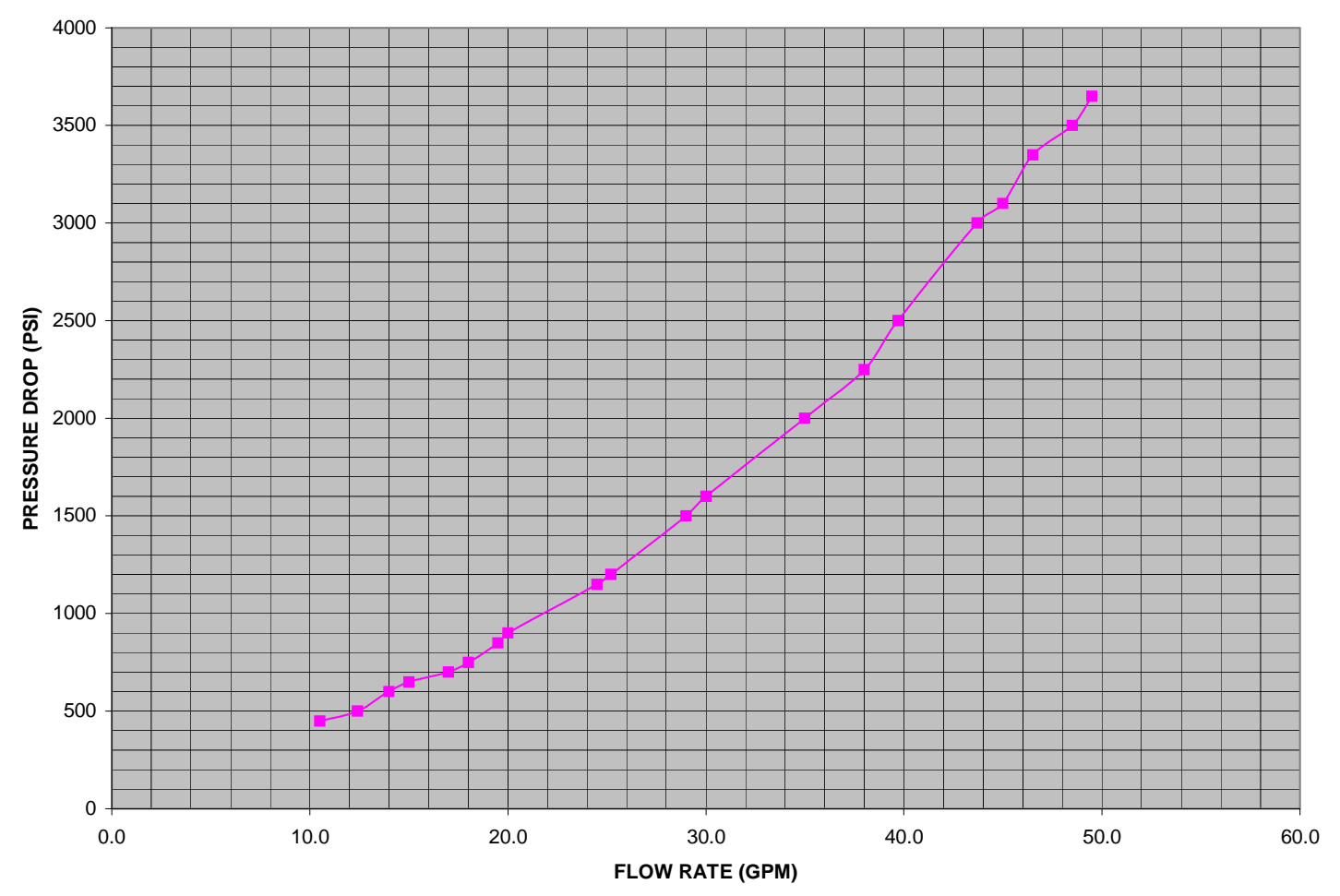

Figure A-3. Pressure Drop Vs. Flow Rate of Table A-1 Data. 


\section{Table A-2 - Drilling Data}

DENNIS TOOL COMPANY - LANL 2.625" CRTMDS TOOL 09/01/2005

RMOTC CASPER, WY

\begin{tabular}{|c|c|c|c|c|c|c|c|c|}
\hline TIME & DEPTH (FT) & WOB (LBS.) & $\begin{array}{c}\text { FLOW RATE } \\
\text { (GPM) }\end{array}$ & $\begin{array}{c}\text { SUFACE } \\
\text { PRESSURE (PSI) }\end{array}$ & $\begin{array}{l}\text { ELAPSED } \\
\text { TIME (HRS) }\end{array}$ & $\begin{array}{c}\text { DEPTH } \\
\text { DRILLED (FT) }\end{array}$ & $\begin{array}{c}\text { AVERAGE } \\
\text { FROM START } \\
\text { ROP (FPH) }\end{array}$ & $\begin{array}{c}\text { OVER } \\
\text { INTERVAL } \\
\text { ROP (FPH) }\end{array}$ \\
\hline 9:30 & 50.0 & 700 & 35 & 3050 & 0.00 & 0.0 & & \\
\hline $9: 42$ & 63.8 & 700 & 35 & 3050 & 0.20 & 13.8 & 69.0 & 69.0 \\
\hline $9: 45$ & 70.5 & 700 & 35 & 3050 & 0.25 & 20.5 & 82.0 & 134.0 \\
\hline $9: 53$ & 81.9 & 700 & 36 & 3050 & 0.38 & 31.9 & 83.2 & 98.7 \\
\hline 10:00 & 93.0 & 700 & 36 & 3050 & 0.50 & 43.0 & 86.0 & 95.1 \\
\hline 10:04 & 101.5 & 700 & 40 & 3450 & 0.57 & 51.5 & 90.9 & 127.5 \\
\hline $10: 10$ & 110.5 & 700 & 40 & 3500 & 0.67 & 60.5 & 90.8 & 90.0 \\
\hline $10: 20$ & 124.5 & 700 & 39 & 3450 & 0.83 & 74.5 & 89.4 & 84.0 \\
\hline $10: 30$ & 137.7 & 700 & 40 & 3400 & 1.00 & 87.7 & 87.7 & 79.2 \\
\hline $10: 40$ & 147.8 & 700 & 39 & 3400 & 1.17 & 97.8 & 83.8 & 60.6 \\
\hline $10: 45$ & 153.5 & 700 & 39 & 3300 & 1.25 & 103.5 & 82.8 & 68.4 \\
\hline $10: 50$ & 158.6 & 700 & 39 & 3400 & 1.33 & 108.6 & 81.5 & 61.2 \\
\hline $11: 00$ & 173.4 & 700 & 39 & 3400 & 1.50 & 123.4 & 82.3 & 88.8 \\
\hline 11:05 & 180.0 & 700 & 39 & 3400 & 1.58 & 130.0 & 82.1 & 79.2 \\
\hline
\end{tabular}

INTERVAL ROP

Dennis Tool 2-5/8" CRTMDS Test at RMOTC 09-01-05

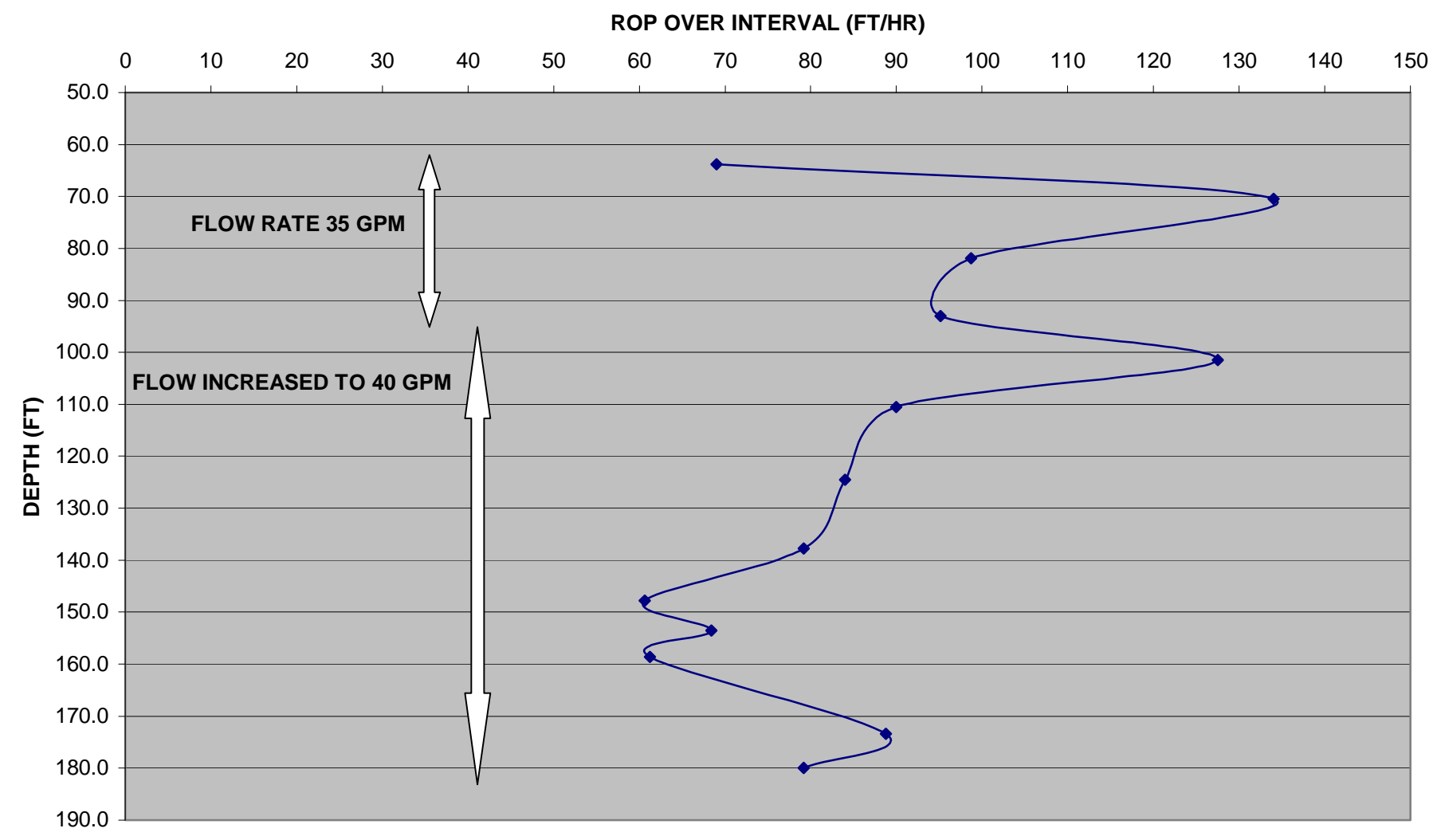

Figure A-4 - Interval ROP of Dennis Tool 2-5/8” CRTMDS Test at RMOTC 


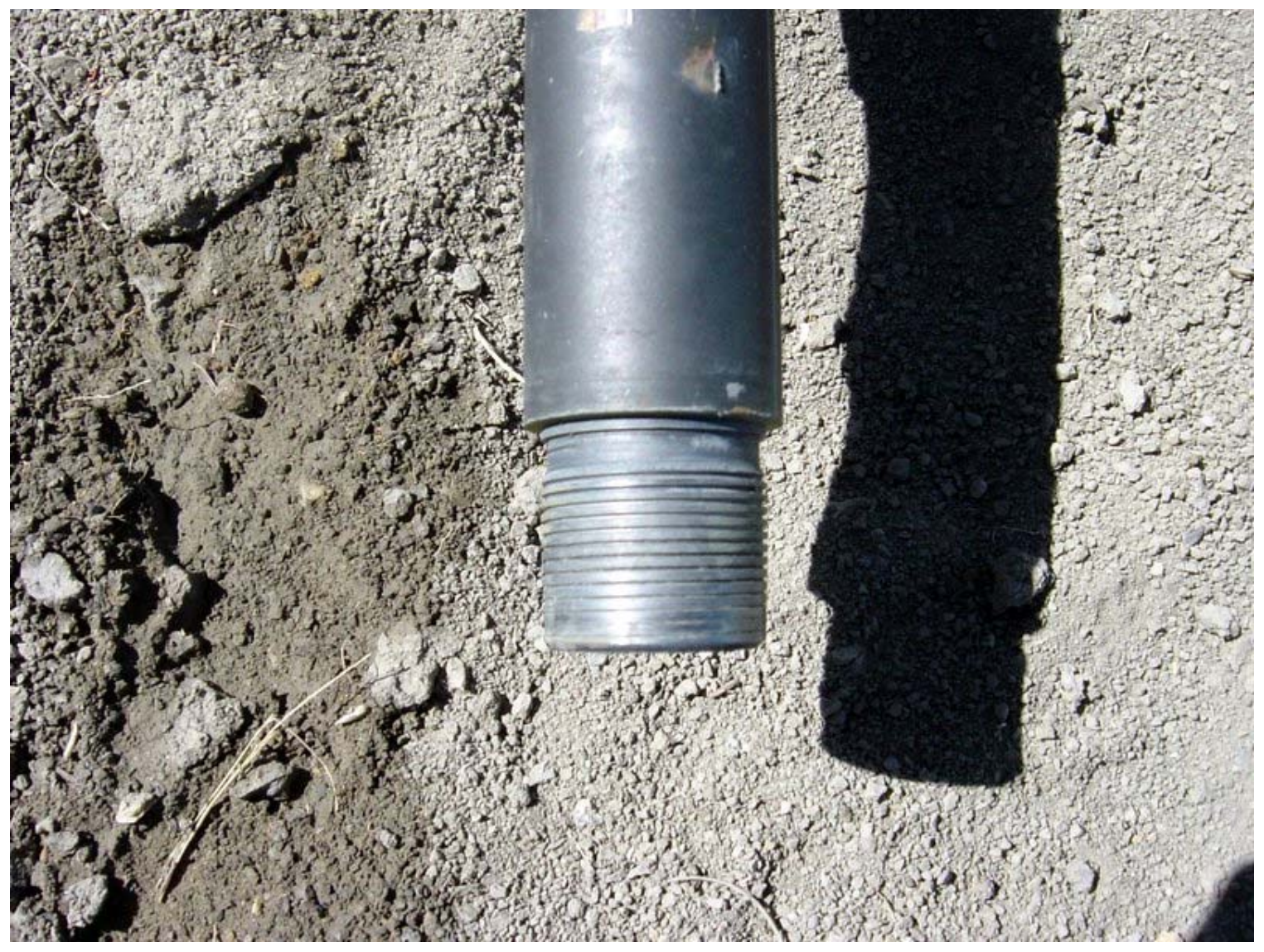

Figure A-5 - Worn Top Sub Connection After Backing Off 


\title{
ATTACHMENT V
}

\author{
Field Test Evaluation Report \\ Los Alamos National Laboratory (LANL) \\ 2-5/8” CRTMDS Tool At Catoosa's Site
}

June 19, 2006

Prepared by:

Eric Twardowski

Dennis Tool Company

Houston, TX 


\section{Objective:}

To evaluate the drilling performance of a Counter-Rotating Tandem Motor Drilling System (CRTMDS) for DOE’s Microhole Technology Initiative.

\section{Background:}

A dual drilling assembly, referred to as the CRTMDS, has been designed and fabricated by Dennis Tool Company for use in the DOE's Microhole Technology (MHT) Initiative. This particular 2-5/8” tool was originally designed for Los Alamos National Laboratories (LANL). A larger 3-1/2” tool is currently being manufactured in conjunction with the MHT project. The CRTMDS includes a left-hand turning positive displacement motor (PDM) and left-hand PDC pilot bit in tandem with a right-hand turning PDM and a right-hand PDC reamer with integral spiral stabilizer (see attached drawing of bottom hole assembly (BHA), appendix A).

An attempt to demonstrate the drilling performance of the 2-5/8” tool was carried out during a field test at the GTI - Catoosa test facility on June 15, 2006. It was anticipated that the dual, counter-rotating cutting assembly should result in a high drilling rate of penetration (ROP) with low weight on bit (WOB), in addition to a reduction in the net reactive torque transmitted to the drillstring. This should complement the limited capabilities available with coiled tubing drilling units.

Previous field testing of this 2-5/8” tool by LANL at the Rocky Mountain Test Facility showed an average rate of penetration of 82 feet per hour. For comparison, this was significantly faster than they had previously been able to drill a 2-5/8” hole size. Using conventional PDC bits and conventional motors, they typically drilled with an ROP in the 10-30 fph range.

The CRTMDS assembly follows DOE work in the original tandem motor project (both motors turning in a right-hand direction) evaluated at RMOTC in October 2004. 


\section{GTI-Catoosa location information:}

Test date: $\quad$ June 15, 2006

Operator: Gas Technology Institute

Location: $\quad$ S25 T21N R14E

County: Rogers

State: $\quad$ Oklahoma

\section{Equipment information:}

Rig: $\quad$ GTI-Catoosa trailer-mounted ring with top drive

Supervisor: $\quad$ Ron Bray / Scott Randolph

Pump: $\quad$ Halliburton HT400 (1.3 gallons per stroke)

PDM's: $\quad$ Right-hand 2-1/16”, 4:5 lobe, 2 stage (rental from BlackMax)

Left-hand 1-1/2”, 1:2 lobe, 3 stage (purchased from Grifco)

Pilot bit: $\quad$ Dennis Tool Company, Left-hand 2-1/8” PDC bit. 5 blades, 7 face cutters (0.375” diameter) at $25^{\circ}$ backrake

Reamer: $\quad$ Dennis Tool Company, Right-hand 2-5/8” PDC reamer with integral 2$1 / 16$ ” spiral stabilizer. 4 blades, 8 face cutters $\left(0.375^{\prime}\right.$ diameter) at $25^{\circ}$ backrake

Flow diverter: To dump excess flow from right-hand PDM before entering lefthand PDM.

Two 3/32” nozzles, Two blank plugs.

Drilling fluid: Clean water, 8.3 ppg

Formation: Sandstone, Limestone, Shale

\section{BHA:}

Crossover for AW connection; 2-1/16” 4:5 lobe 2 stage right-hand PDM; 2-5/8” reamer with integral 2-1/16" stabilizer; flow diverter with two 3/32"nozzles and two blank plugs; 1-1/2” 1:2 lobe 3 stage left-hand PDM; 2-1/8” left-hand pilot bit. (Overall length of BHA = 19.81 feet) 
(see photos Appendix B)

\section{Test summary:}

A first attempt to evaluate the tool was made on June 06, 2006. The TD of the existing well was supposedly 425'. The CRTMDS was run in the hole to a depth of 588' without ever tagging bottom. There was a discrepancy regarding the actual depth of the existing well. It was determined that the actual depth was unknown. After looking into the matter further, GTI-Catoosa speculated that the wellbore might be horizontal and there might also be a cement plug in the wellbore. A decision was made to set a cement plug, kick off, and drill to a depth just below the Verdigris Limestone. The evaluation of the CRTMDS was postponed until this work was completed.

Prior to our arrival, the top of the cement plug (in 7" casing) was at 75'. It was dressed down to 194' (32' below the shoe). The hole was sidetracked using a 4-3/4" three cone rock bit driven by a PDM with $1-1 / 2^{\circ}$ bend. Drilling $100 \%$ formation achieved at 300-330'. The 4-3/4" hole was drilled to 360' measured depth. (see sketch Appendix C)

The CRTMDS was assembled prior to picking up the tool. Loc-Tite thread lock was used to secure all connections between each component in the BHA. According to Grifco, all internal threaded connections on the 1-1/2” left-hand PDM were also secured with thread lock.

The CRTMDS was run in the hole at 07:50 with the pump off to a depth of 335' (10 joints of drill pipe). This was done in an effort to avoid re-sidetracking the well. After repairing a malfunctioning pressure gage, the swivel was connected and the pump engaged. Initial flow rate was set at 18 strokes, or 23 gpm. Pump pressure read 500-700 psi, with a cyclical $200 \mathrm{psi}$ fluctuation noted. The drillstring was set to turn at $34 \mathrm{rpm}$. 
The tool tagged bottom at 360'. WOB was applied very gradually. Whenever WOB exceeded approximately 500 lbs., the pump pressure increased rapidly to about 1000 psi, indicating a stall condition on one of the PDM's.

After drilling with very low ROP to a depth of 367' (7’ drilled in 30 minutes, 14 $\mathrm{fph})$, the flow rate was increased to 23 strokes per minute (30 gpm). This was done in an effort to improve ROP. It should be noted that 8-1/2" PDC bits typically drill $150 \mathrm{fph}$ in this formation. The CRTMDS was drilling significantly slower than a conventional bit.

Soon after increasing the flow rate, the pressure relief on the HT400 mud pump sheared a nail. The nail was replaced, and drilling resumed. After a few minutes, the pump sheared another nail. Drilling progressed, but was very slow at 12-20 fph. After continued shearing of nails on the pressure relief, drilling was halted and a crew member traveled to the hardware store to get larger nails. Down time was about one hour.

A larger nail was installed, and drilling resumed. The larger nails did not shear as often as the smaller nails, but the pump did shear at least four of the large nails.

At a depth of 375', ROP was still very low. In an attempt to improve ROP, the flow rate was increased to 28 strokes / min, 37 gpm. At 2:00 p.m., the driller (Rick) noticed a change in drillstring vibration. This coincided with a reduction in ROP. We stopped the rotary and could actually feel by hand a variation in vibration on drillstring. A crew member checked the screen on the flow line returns and found very thin black shavings or flakes. There were also a few orange flakes visible in the screen. We thought this could be possibly paint from the outside of the Black Max Motor (these motors are painted orange and black), or it could possibly be rubber shavings. Perhaps from a damaged a stator.

The CRTMDS drilled to a depth of 382' with an average ROP of only 13 fph (22' drilled in 1.69 hrs). Based on the unusual vibration, possible rubber in the flow line screen, and low ROP, we opted to pull out of the hole and examine the BHA. The BHA 
was out of the hole at 2:45 p.m. All components were examined and found to be intact. All PDC cutters were in very good condition with no wear. Some polishing was noted on the outside of the left-hand PDM indicating possible contact with the borehole.

With the tool still hanging in the derrick, we tried to manually rotate the output shaft of both PDM's. Both could be turned with a pipe wrench.

The swivel was then connected to the BHA at surface and the pump was engaged. We could see that the right hand PDM was running erratically. It would rotate then stop, rotate then stop, repeatedly, in a very regular, cyclical fashion. At this point, we assumed that there was a problem with the right-hand Black Max PDM.

The remainder of the BHA was then disassembled. A small chunk of rubber was discovered in one of the nozzle ports on the pilot bit. It was uncertain where this chunk of rubber came from.

In order to isolate the problem, we then connected only the right-hand PDM to the swivel. When the HT400 pump was engaged, we could see clearly that the rotation was erratic. The output shaft would spin and then stop repeatedly. We also noticed that the fluid exiting the PDM was pulsing on and off, good flow followed by little or no flow. These observations indicated that there might be a problem with the HT400 pump.

There was a smaller Gardner Denver PW3H pump available, so we decided to hook it up to the rig. The right-hand PDM now rotated very smoothly and the RPM matched the flow rate perfectly.

The GTI-Catoosa crew disassembled the HT400 pump and discovered a problem. There was a broken seal on the center piston valve. This pump has three pistons.

According to the crew, this problem would definitely cause an erratic flow rate. Probably averaging approximately $2 / 3$ or less of the expected flow rate for a given 
number of strokes per minute. This would explain the poor ROP and also the 200 psi pulsations seen in the pump pressure. When the mud flow slowed, or stopped, the bit would "bite in" to the formation. When the flow increased, we would see a pressure increase indicating a stall condition. This forced us to keep backing off the WOB and keep it below 500-700 lbs., thus causing low ROP.

Effectively the flow was varying from 0 to $37 \mathrm{gpm}$ (at 23 strokes / minute). This would cause the output shaft on the right-hand PDM to cycle from 0 to 200 rpm and back to zero, twenty-three times per minute. The left-hand PDM would cycle in a similar fashion.

After all tools were laid down, we discussed options for continuing the test. The Halliburton HT400 pump needs a complete, thorough inspection on the fluid end. According to the crew, this is a very time consuming process. Since this work could not be completed in time to allow for testing the following day, we considered the possibility of using the smaller Gardner Denver pump.

A check was made on the characteristics of the GD pump. It was calculated that the pump had 4" liners, which would have a pressure rating of 380 psi. This low pressure rating would not be sufficient for operating the CRTMDS. There were no other pumps available to operate the CRTMDS.

Since we heard the "mechanical” noise / vibration while drilling, and saw possible rubber in the returns, we felt it would be wise to tear down both PDM's and inspect them before re-running. In hindsight, it is likely that the vibration was occurring the entire time that we were drilling. We only noticed the vibration on the drill string after we increased the flow rate to $37 \mathrm{gpm}$. The on/off pulsing was amplified by the higher flow rate, and we were able to detect it at surface once it became severe enough. 


\section{Conclusions:}

Initially, the low ROP of the tool was very puzzling. But, after discovering that the bit was going from zero to maximum rpm and back to zero with every pump stroke cycle, it is not surprising that the drilling performance was poor.

According to the GTI-Catoosa crew, the HT400 pump needs a complete fluid end inspection, and possible overhaul. These repairs are time consuming and could not be completed in time to allow for testing the following day. The smaller Gardner Denver pump with 4" liners has too low a pressure rating to operate the CRTMDS. There were no other pumps available to run the CRTMDS.

At the same time, we felt it would be prudent to tear down and inspect both PDM's for possible internal damage before re-running them.

Because of the pump situation, no conclusions can be drawn in regards to tool performance from this most recent test.

\section{Plans for future testing:}

The 2-5/8” CRTMDS will be shipped back to Dennis Tool for evaluation. Both PDM's will then be returned to the manufacturer to be disassembled and inspected for signs of wear. Any damaged components will be repaired.

We would like to attempt another evaluation of this tool after the mud pump has been repaired.

The new 3-1/2" CRTMDS is nearing completion. It may be best to wait until the 3-1/2” tool is completed before scheduling a future evaluation at GTI-Catoosa. This would allow us to field test both tools during the same trip to Catoosa. 
Appendix A - BHA of 2-5/8” CRTMDS Catoosa Evaluation 06-15-06

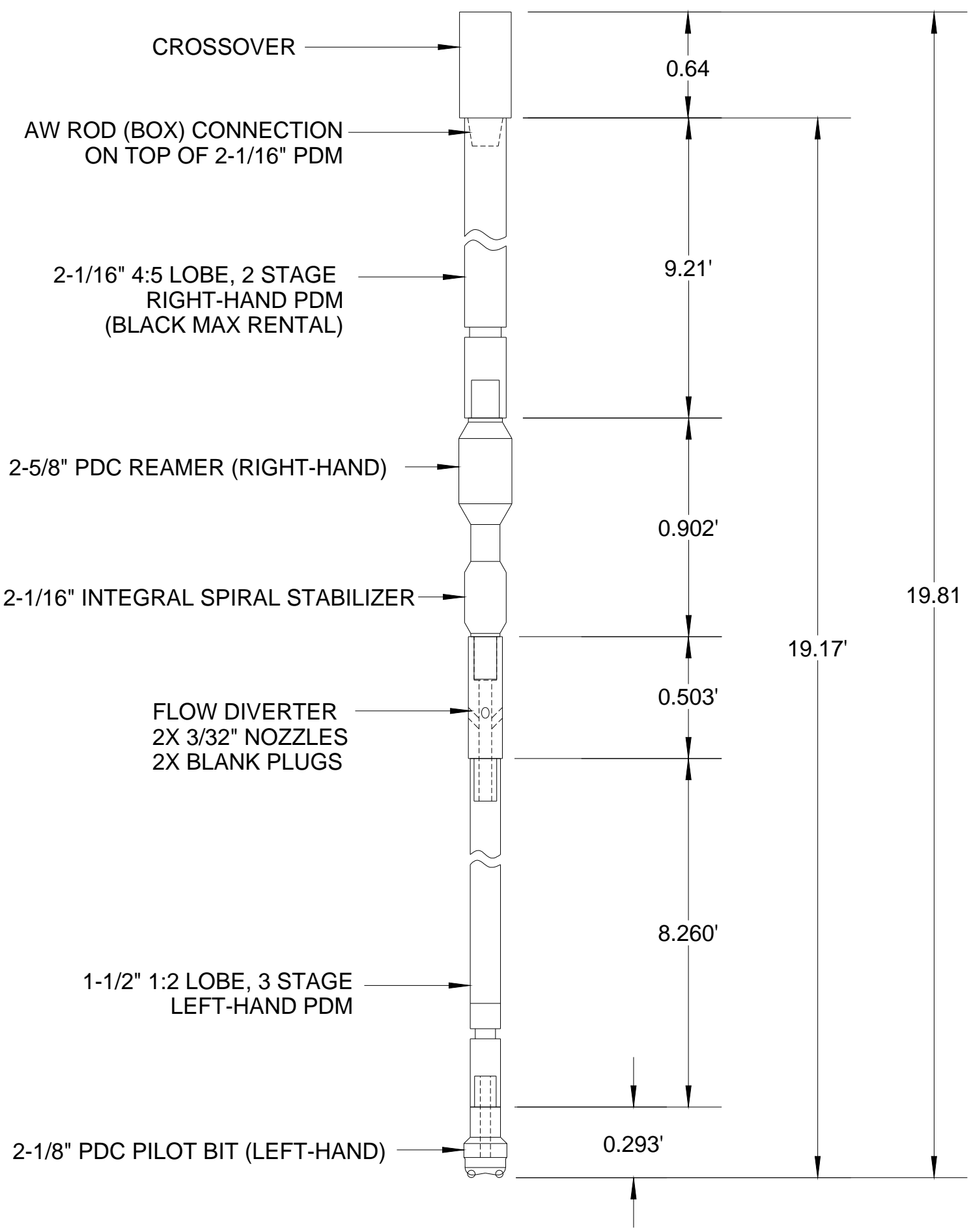


Appendix B - Photo of Tool Components

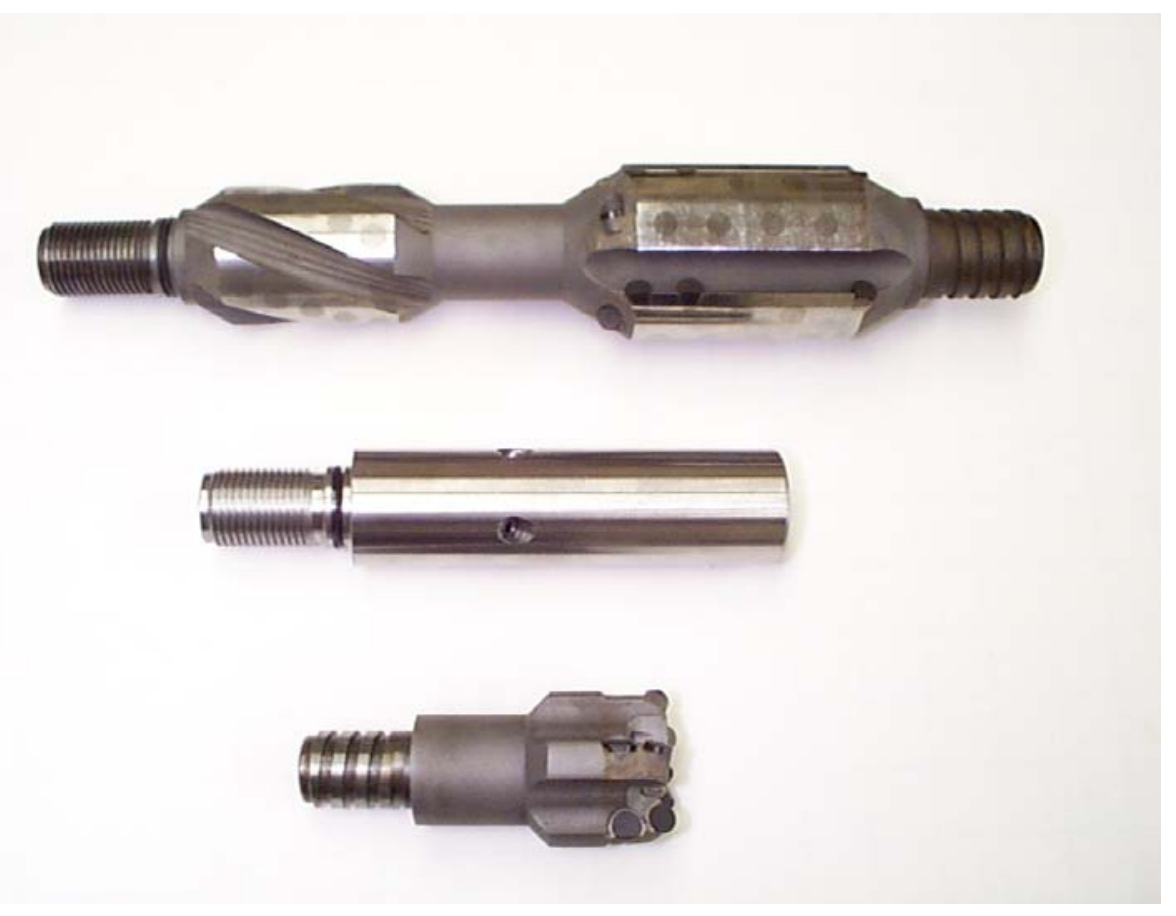

Reamer / stabilizer (top), Flow diverter (middle), Pilot bit (bottom) 
Appendix C - Hole Condition Prior to Testing

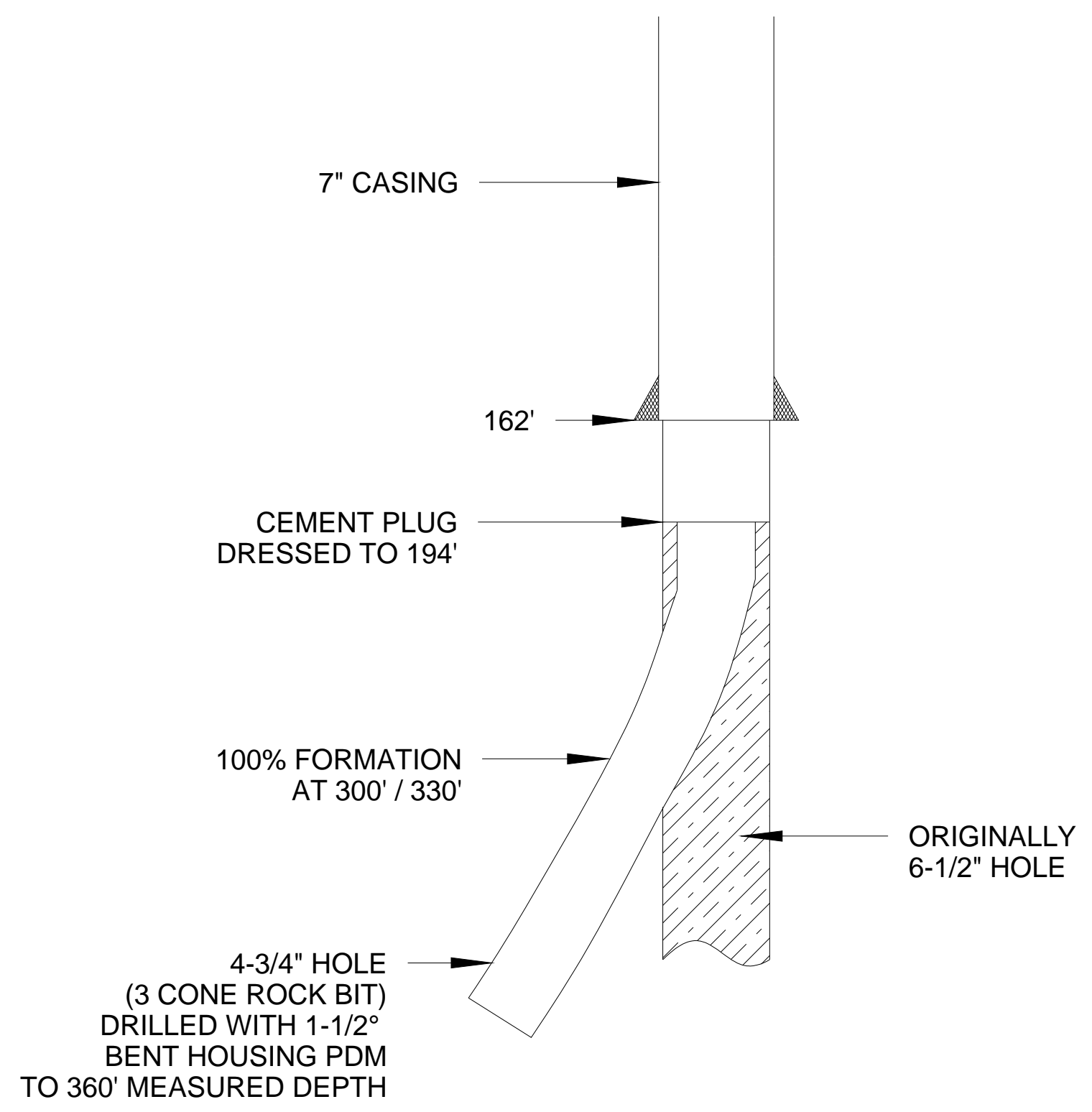




\section{ATTACHMENT VI}

Field Test Evaluation Report

3-1/2” Counter-Rotating Tandem Drilling System Tool At Gti-Catoosa

March 26-28, 2007

Prepared by:

Eric Twardowski

Dennis Tool Company

Houston, TX 


\section{Objective:}

To evaluate the drilling performance of a Counter-Rotating Tandem Motor Drilling System (CRTMDS) for DOE’s Microhole Technology Initiative.

\section{Background:}

A dual drilling assembly, referred to as the CRTMDS, has been designed and fabricated by Dennis Tool Company for use in the DOE's Microhole Technology (MHT) Initiative. The CRTMDS includes a left-hand turning positive displacement motor (PDM) and left-hand PDC pilot bit in tandem with a right-hand turning PDM and a righthand PDC reamer with stabilizer (see attached drawing of bottom hole assembly (BHA), appendix A).

The objective of this test was to demonstrate the drilling performance of the 3$1 / 2$ ” tool during a field test at the GTI - Catoosa test facility. The testing took place March 26-28, 2007. It was anticipated that the dual, counter-rotating cutting assembly should result in a high drilling rate of penetration (ROP) with low weight on bit (WOB), in addition to a reduction in the net reactive torque transmitted to the drillstring. This should complement the limited torque and weight capabilities available with coiled tubing drilling units.

Previous field testing of a similar, but smaller 2-5/8” tool by LANL at the Rocky Mountain Oilfield Testing Center (RMOTC) showed an average rate of penetration of 82 feet per hour. For comparison, this was significantly faster than they had previously been able to drill a 2-5/8” hole size. Using conventional PDC bits and conventional motors, they typically drilled with an ROP in the 10-30 fph range.

The CRTMDS assembly follows DOE work in the original tandem motor project (both motors turning in a right-hand direction) evaluated at RMOTC in October 2004.

\section{GTI-Catoosa location information:}

Test date: $\quad$ March 26-28, 2007 
Operator: Gas Technology Institute

Location: $\quad$ S25 T21N R14E

County: Rogers

State: $\quad$ Oklahoma

\section{Equipment information:}

Rig: $\quad$ GTI-Catoosa trailer-mounted ring with top drive RT-2000 (single)

Supervisor: Ron Bray / Scott Randolph

Pump: $\quad$ Halliburton HT400 (1.3 gallons per stroke)

PDM's: $\quad$ Right-hand 2-7/8”, 7:8 lobe, 3 stage (rental from Wenzel)

Left-hand 2-1/8”, 1:2 lobe, 2.5 stage (purchased from Wenzel)

Pilot bit: $\quad$ Dennis Tool Company, Left-hand 2-3/4” PDC bit. 5 blades, 8 face cutters, 5 trimmers ( $0.375^{\prime \prime}$ diameter) at $25^{\circ}$ backrake

Reamer: $\quad$ Dennis Tool Company, Right-hand 3-1/2” PDC reamer welded to 211/16” stabilizer. 4 blades, 8 face cutters, 8 trimmers (0.375” diameter) at $25^{\circ}$ backrake

Drilling fluid: Clean water, 8.3 ppg

Formation: Limestone, Shale, Sandstone

\section{BHA:}

2-7/8” 7:8 lobe 3 stage right-hand PDM; 3-1/2” PDC reamer (right-hand) welded to 2-11/16" stabilizer; 2-1/8” 1:2 lobe 2.5 stage left-hand PDM; 2-3/4” left-hand PDC pilot bit. (Overall length of BHA = 26.52 feet). Due to the non-standard 2-1/16” firestick drillpipe connection, a crossover sub was welded to one joint of 2-1/16" firestick drillpipe. Length of the joint of drillpipe with welded crossover $=32.18$ feet. (See photos Appendix B)

\section{Test summary:}

Prior to this test, several other attempts were made to evaluate the 3-1/2" CRTMDS at the Catoosa Test Facility. All previous testing at Catoosa was inconclusive due to rig and hole problems. 
Prior to our arrival at the Catoosa Test Facility, a new well was drilled to ensure that no obstructions (casing, tubing, doglegs, etc.) were present. The well was drilled to a depth of 164 feet (below the top of the riser) and 7" casing was set. Since the CRTMDS tool is a rather small diameter, the decision was made to set a 5-1/2" liner inside of the 7" casing. The 5-1/2” liner provides higher annular velocity for removal of cuttings. Both the 7" casing and 5-1/2" liner were set down to the initial TD of 164 feet. All measurements recorded in this report are referenced from the top of the riser. The riser was approximately 5 feet above ground level.

The CRTMDS creates left-hand torque with the pilot bit and right-hand torque with the reamer. Ideally, these torques will balance each other for a net of zero reactive torque transmitted to the drillstring. However, there is the potential that in some instances the left-hand torque will be greater than the right-hand torque. Due to concerns about connections possibly backing off while drilling, several precautions were taken in order to limit the potential for back-offs.

First, all threaded connections within the BHA (with the exception of internal components on the right-hand PDM) were secured with Loctite high strength threadlocking compound.

Second, where possible the connections were also welded. The left-hand pilot bit was welded to the output shaft of the left-hand PDM. The reamer and stabilizer were also welded together. Originally the stabilizer was designed to be integral to the reamer (machined from a solid piece). But, due to size limitations with the milling machine, the reamer and stabilizer had to be manufactured as two separate pieces. The connection between the reamer and stabilizer was threaded and welded. 
Finally, a "starter hole" was drilled 15 feet past the initial TD of the well. The purpose of the "starter hole" is to ensure that the right-hand reamer engages the formation and generates right-hand torque, before the left-hand pilot bit starts to drill. The reamer and pilot bit are about 14 feet apart.

For this evaluation, prior to entering the well with the 3-1/2" CRTMDS, a 215/16" diameter "starter hole” was drilled with a three-bladed tungsten carbide spade bit. This diameter was selected because it is slightly larger than the 2-3/4” pilot bit, and smaller than the 3-1/2” reamer. The 2-15/16” hole was drilled on rotary with an ROP of $30 \mathrm{fph}$. The following parameters were used: 40 rpm, 65 gpm flow, 400 psi, 1000-2000 lb WOB. This "starter hole" was drilled to a depth of 179 feet (15 feet deeper than the original TD of 164 feet).

After drilling the "starter hole" the 3-1/2" CRTMDS was rigged up and run in the hole. The tool started drilling at a depth of 178 feet. Initially, the flow rate was set to 65 gpm, and weight on bit was kept as light as possible. The drillstring rotated at $20 \mathrm{rpm}$. This resulted in an ROP of $28 \mathrm{fph}$ for the first 7 feet drilled.

More detailed drilling data can be found in Appendix C. Data points were manually recorded about every five feet. Following is a general description of the drilling performance of the CRTMDS.

At a depth of 185 feet, the weight on bit was increased to about 1000 lbs. The drillstring was not rotated. ROP increased to about $72 \mathrm{fph}$ in the shale formation (31 feet in 26 minutes).

At a depth of 216 feet, the flow rate was increased to 78 gpm. This is about the maximum allowable for the left hand PDM and was also about the maximum flow available with the HT400 pump. Increasing the flow rate dramatically improved ROP to 
about 149 fph (72 feet in 29 minutes) while drilling shale. There were several five-foot intervals that drilled at $200 \mathrm{fph}$.

Limestone was encountered at 288 feet. This slowed ROP significantly. Weight on bit was increased to 2000 - 2500 lbs. The added weight improved the drilling performance. Limestone, shale, and sandstone were drilled from 288 feet to 342 feet with an average ROP of $51 \mathrm{fph}$ (54 feet in 64 minutes). At this point, the rig was shut down for the night.

The following morning, March $28^{\text {th }}$, drilling resumed. Drilling parameters were 78 gpm flow rate and 2000 to 2500 lbs weight on bit. The first joint of pipe drilled from 342 feet to 374 feet, with an average ROP of 128 fph (32 feet in 15 minutes)

Drilling continued at a similar ROP down to a depth of 382 feet. At this point drilling slowed significantly to about 56 fph (20 feet in 21.5 minutes). At depth of 402 feet, the CRTMDS stopped drilling. A significant drop ( 500 psi) in the surface pressure was noted. This pressure drop indicated than part of the BHA may have backedoff downhole. The decision was made to pull out of the hole.

The drillpipe, right-hand PDM, and PDC reamer were retrieved. The stabilizer, left-hand PDM, and left-hand pilot bit were still in the hole. The connection between the reamer and stabilizer had backed-off. This particular connection had been welded together, but it appeared that the weld cracked. The threaded pin down connection on the reamer was in very good condition. 
Options for fishing were then discussed. The top of the fish was rather short, so a conventional overshot was not an option. The ID of the fish was rather small, so a conventional tap was not an option. Since the threads on the reamer were in good condition, the decision was made to trip the reamer back down the hole and try to screw it into the top of the fish. After tripping in with the reamer, the drillpipe was turned by hand. We were not able to screw into the fish. The drillpipe was then connected to the swivel and rotated. There were no indications that we were successful in making the connection to the fish.

The decision was made to pull out of hole $(\mathrm{POOH})$ and go back down with a modified tap. Surprisingly, when we got back to surface, we actually did have the fish. It was literally "hanging by a thread". (See photos in Appendix D). It was also noted that the connection between the power section and bearing section of the left hand PDM had also backed off. Due to thread damage at both of these connections, no further testing could be performed. The tool will be shipped back to Houston for disassembly and inspection. All PDC cutters on the pilot bit and reamer were in excellent condition. No wear or chipping was noted.

\section{Conclusions:}

This evaluation demonstrated that the counter-rotating tandem motor system can effectively drill with a high rate of penetration and low weight on bit. A total of 224 feet of shale, limestone, and sandstone were drilled in 3 hours (75 fph overall average). ROP reached $200+$ fph in some shale intervals.

A better method for limiting left-hand torque, limiting vibration, and securing downhole connections is needed.

\section{Plans for future testing:}

As mentioned above, this evaluation proved the drilling performance of the CRTMDS. It would be possible to repair the reamer, stabilizer, and left-hand PDM. 
However, repairing these and re-evaluating them would likely not produce much more useful information than we have already obtained.

Past evaluations of this tool and a similar, but smaller tool built for testing by LANL have shown the need for more reliable small diameter drilling motors.

Dennis Tool Company is currently working on a design concept for a shortlength, small-diameter drilling motor. This new type of motor should be a very reliable tool. We plan to use some of the remaining funding for this project to develop a new type of drilling motor. The short length (less than three feet) would be extremely beneficial for a tandem motor drilling system. The motor could also be designed with mechanisms for preventing connections from backing off as well as reverse rotation. 


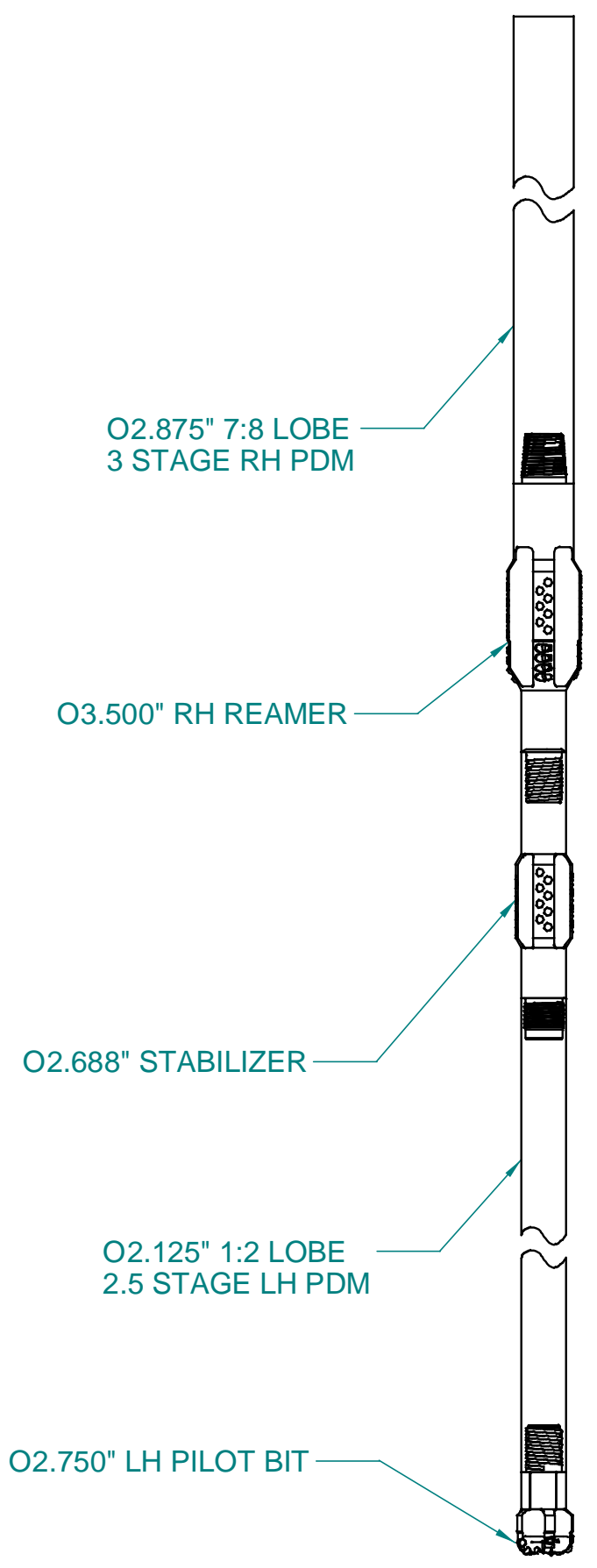

Appendix A - BHA of 3-1/2” CRTMDS Catoosa Evaluation 03-27-07 
Appendix B - Photos of Pilot Bit, Reamer, and Stabilizer
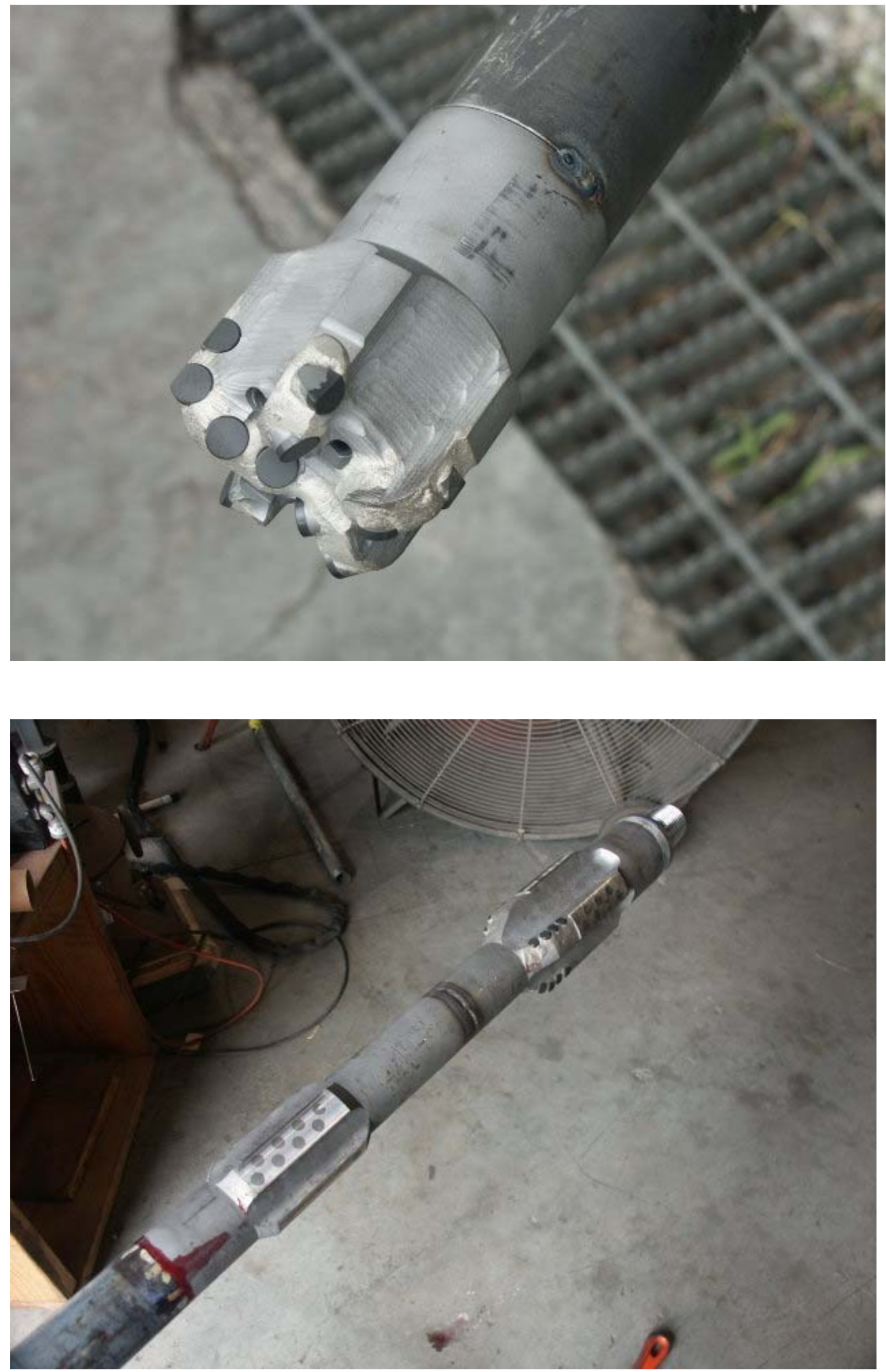


\section{Appendix C - Drilling Data}

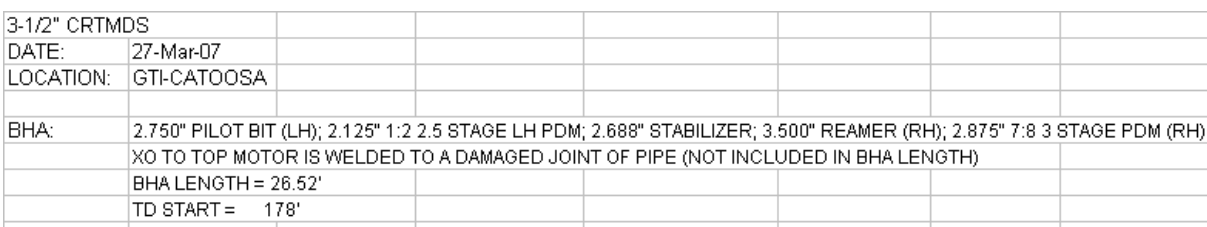

\begin{tabular}{|l|l|l|l|l|l|l|l|}
\hline DEPTH (FT) & TIME OF DAY & DELTA (MIN) & ROP (FPH) & FLOW RATE (GPM) & PUMP PSI & WOB (LBS.) & TORQUE (FT-LB) \\
\hline
\end{tabular}

\begin{tabular}{|c|c|c|c|c|c|c|c|}
\hline & & & & & & & \\
\hline 178 & $14: 25$ & & & \begin{tabular}{l|}
65 \\
\end{tabular} & $900-1100$ & 1000 & 260 \\
\hline 183 & $14: 35$ & 10.00 & 30.0 & 65 & $900-1100$ & 1000 & 50 \\
\hline 185 & $14: 40$ & 5.00 & 24.0 & 65 & $900-1100$ & 1000 & 50 \\
\hline \multicolumn{8}{|c|}{ MAKE CONNECTION } \\
\hline 185 & $14: 53$ & & & 65 & $900-1100$ & 1000 & 10 \\
\hline 189 & $14: 58$ & 5.00 & 48.0 & 65 & $900-1100$ & 1000 & 10 \\
\hline 190 & $14: 59$ & 1.00 & 60.0 & 65 & $900-1100$ & 1000 & 10 \\
\hline 195 & $15: 03$ & 4.00 & 75.0 & 65 & $900-1100$ & 1000 & 10 \\
\hline 200 & $15: 06$ & 2.75 & 109.1 & 65 & $900-1100$ & 1000 & 10 \\
\hline 205 & 15:10 & 4.00 & 75.0 & 65 & $900-1100$ & 1000 & 10 \\
\hline 210 & $15: 14$ & 3.66 & 82.0 & 65 & $900-1100$ & 1000 & 10 \\
\hline 215 & $15: 18$ & 3.83 & 78.3 & 65 & $900-1100$ & 1000 & 10 \\
\hline 216 & $15: 19$ & 0.83 & 72.3 & 65 & $900-1100$ & 1000 & 10 \\
\hline \multicolumn{8}{|c|}{ MAKE CONNECTION } \\
\hline 216 & $15: 45$ & & & 78 & $1200-1400$ & 1000 & -50 \\
\hline 221 & $15: 47$ & 2.25 & 133.3 & 78 & $1200-1400$ & 1000 & -50 \\
\hline 226 & $15: 48$ & 1.58 & 189.9 & 78 & $1200-1400$ & 1000 & -50 \\
\hline \multicolumn{8}{|c|}{ REPAIR LEAK 3 MINUTES } \\
\hline 227 & $15: 51$ & & & 78 & $1200-1400$ & 1000 & -50 \\
\hline 231 & $15: 53$ & 1.50 & 160.0 & 78 & $1200-1400$ & 1000 & -50 \\
\hline 236 & $15: 55$ & 1.83 & 163.9 & 78 & $1200-1400$ & 1000 & -50 \\
\hline 241 & $15: 57$ & 1.92 & 156.3 & 78 & $1200-1400$ & 1000 & -50 \\
\hline 246 & $15: 59$ & 2.75 & 109.1 & 78 & $1200-1400$ & 1000 & -50 \\
\hline 248 & $16: 00$ & 0.67 & 179.1 & 78 & $1200-1400$ & 1000 & -50 \\
\hline \multicolumn{8}{|c|}{ MAKE CONNECTION } \\
\hline 248 & $16: 12$ & & & 78 & $1200-1400$ & 1000 & -50 \\
\hline 253 & $16: 15$ & 2.42 & 124.0 & 78 & $1200-1400$ & 1000 & -50 \\
\hline 258 & $16: 17$ & 1.83 & 163.9 & 78 & $1200-1400$ & 1000 & -50 \\
\hline 263 & $16: 18$ & 1.33 & 225.6 & 78 & $1200-1400$ & 1000 & -50 \\
\hline 268 & $16: 19$ & 1.53 & 196.1 & 78 & $1200-1400$ & 1000 & -60 \\
\hline 273 & $16: 22$ & 2.58 & 116.3 & 78 & $1200-1400$ & 1000 & -60 \\
\hline 278 & $16: 25$ & 2.00 & 150.0 & 78 & $1200-1400$ & 1000 & -60 \\
\hline 279 & $16: 25$ & 0.50 & 120.0 & 78 & $1200-1400$ & 1000 & -60 \\
\hline \multicolumn{8}{|c|}{ MAKE CONNECTION } \\
\hline 279 & $16: 37$ & & & 78 & $1200-1400$ & 1000 & -60 \\
\hline 284 & $16: 39$ & 1.87 & 160.4 & 78 & $1200-1400$ & 1000 & -60 \\
\hline 287 & $16: 41$ & 1.66 & 108.4 & 78 & $1200-1400$ & 1000 & -60 \\
\hline 288 & $16: 43$ & 1.00 & 60.0 & 78 & $1200-1400$ & 1000 & -60 \\
\hline 289 & $16: 43$ & 1.00 & 60.0 & 78 & $1200-1400$ & 1000 & -60 \\
\hline 290 & $16: 44$ & 1.00 & 60.0 & 78 & $1200-1400$ & 1000 & -60 \\
\hline 294 & $16: 48$ & 4.33 & 55.4 & 78 & $1200-1400$ & 1000 & -60 \\
\hline 299 & $16: 55$ & 6.50 & 46.2 & 78 & $1200-1400$ & 1000 & -60 \\
\hline 304 & $17: 04$ & 9.00 & 33.3 & 78 & $1200-1400$ & 2000 & -50 \\
\hline 309 & $17: 14$ & 10.00 & 30.0 & 78 & $1200-1400$ & 2000 & -50 \\
\hline 311 & $17: 15$ & 1.80 & 66.7 & 78 & $1200-1400$ & 2000 & -50 \\
\hline \multicolumn{8}{|c|}{ MAKE CONNECTION } \\
\hline 311 & $17: 40$ & & & 78 & $1200-1400$ & 2000 & -20 \\
\hline 316 & $17: 46$ & 6.25 & 48.0 & 78 & $1200-1400$ & 2000 & -20 \\
\hline 321 & $17: 53$ & 6.83 & 43.9 & 78 & $1200-1400$ & 2000 & -30 \\
\hline 326 & $17: 57$ & 4.25 & 70.6 & 78 & $1200-1400$ & 2000 & -30 \\
\hline 331 & $18: 02$ & 4.33 & 69.3 & 78 & $1200-1400$ & 2000 & -30 \\
\hline 336 & 18:08 & 6.28 & 47.8 & 78 & $1200-1400$ & 2000 & -30 \\
\hline 341 & 18:11 & 3.10 & 96.8 & 78 & $1200-1400$ & 2000 & -30 \\
\hline 342 & 18:12 & 0.67 & 89.6 & 78 & $1200-1400$ & 2000 & -30 \\
\hline \multicolumn{8}{|c|}{ MAKE CONNECTION AND STOP FOR NIGHT } \\
\hline 342 & $7: 52$ & & & 78 & $1200-1400$ & 2000 & -30 \\
\hline 347 & $7: 56$ & 4.00 & 75.0 & 78 & $1200-1400$ & 2000 & -30 \\
\hline 352 & $7: 58$ & 1.67 & 179.6 & 78 & $1200-1400$ & 2000 & -30 \\
\hline 357 & $7: 59$ & 1.75 & 171.4 & 78 & $1200-1400$ & 2000 & -30 \\
\hline 362 & $8: 01$ & 1.75 & 171.4 & 78 & $1200-1400$ & 2000 & -30 \\
\hline 367 & $8: 03$ & 2.00 & 150.0 & 78 & $1200-1400$ & 2000 & -30 \\
\hline 372 & $8: 05$ & 2.50 & 120.0 & 78 & $1200-1400$ & 2000 & -30 \\
\hline 374 & $8: 07$ & 0.80 & 150.0 & 78 & $1200-1400$ & 2000 & -30 \\
\hline \multicolumn{8}{|c|}{ MAKE CONNECTION } \\
\hline 374 & $8: 16$ & & & 78 & $1300-1500$ & 2000 & -30 \\
\hline 379 & $8: 19$ & 3.00 & 100.0 & 78 & $1300-1500$ & 2000 & -30 \\
\hline 382 & $8: 20$ & 1.50 & 120.0 & 78 & $1300-1500$ & 2000 & -40 \\
\hline 384 & $8: 24$ & 4.00 & 30.0 & 78 & $1300-1500$ & 2000 & -40 \\
\hline 389 & 8:31 & 7.00 & 42.9 & 78 & $1300-1500$ & 2000 & -50 \\
\hline 394 & $8: 37$ & 6.00 & 50.0 & 78 & $1300-1500$ & 2000 & -50 \\
\hline 399 & $8: 43$ & 5.50 & 54.5 & 78 & $1300-1500$ & 2000 & -40 \\
\hline \begin{tabular}{l|l}
402 & \\
\end{tabular} & $8: 46$ & 3.00 & 60.0 & 78 & $1300-1500$ & 2000 & -40 \\
\hline
\end{tabular}




\section{ROP DATA - 3.500" CRTMDS CATOOSA MARCH 2007}

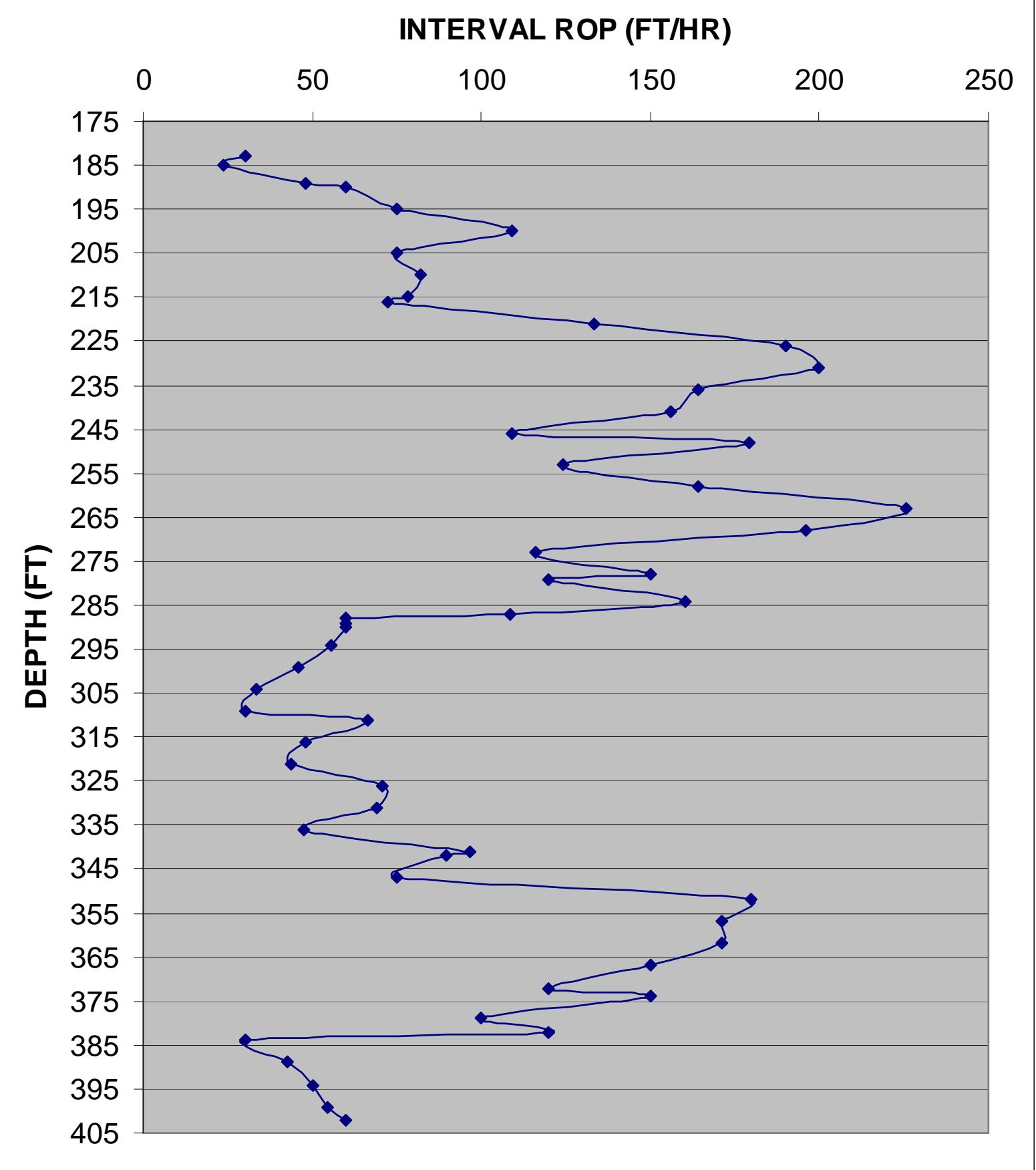


Appendix D - Photos of Connections After Fishing
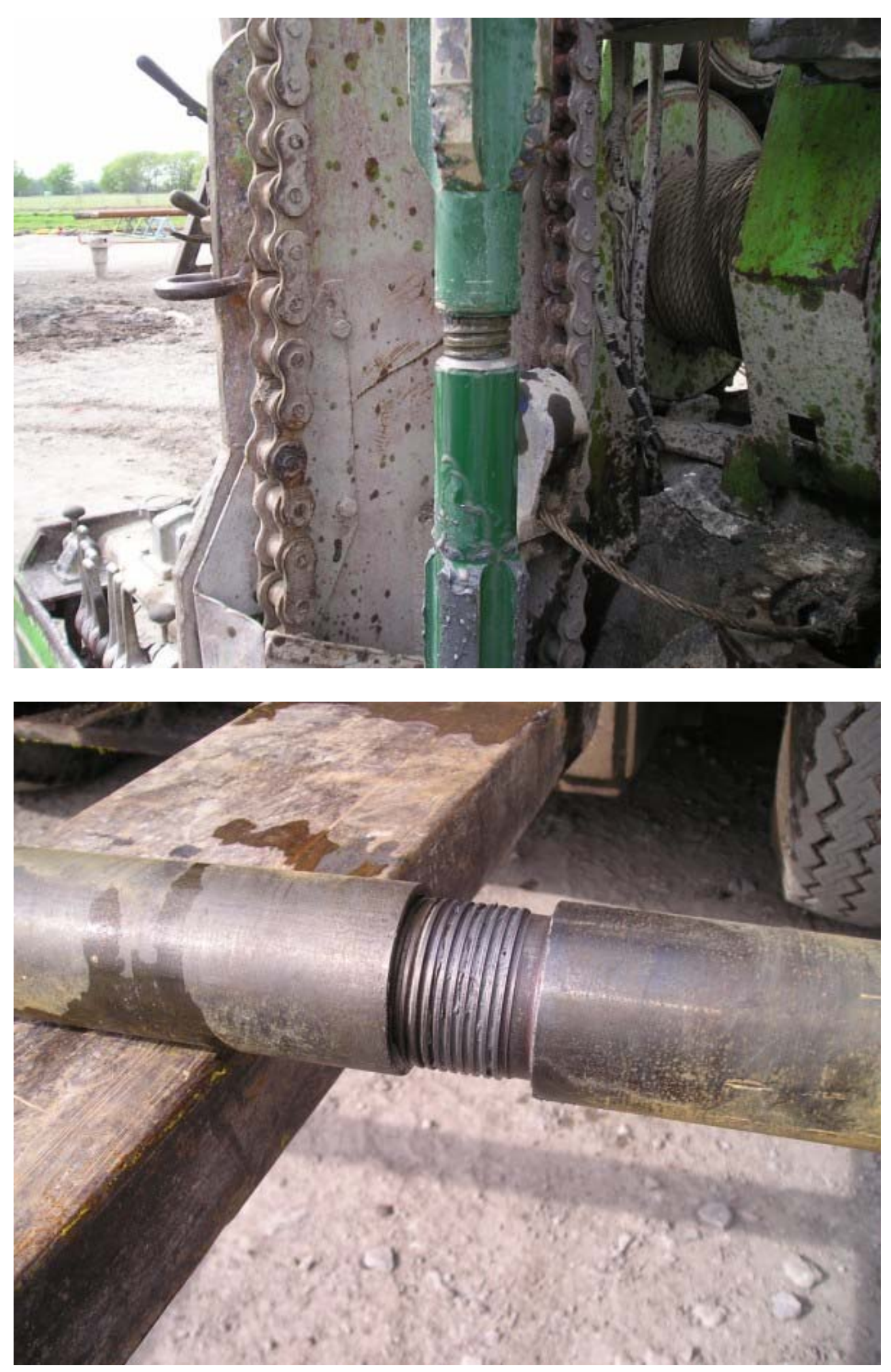


\section{ATTACHMENT VII}

Field Test Evaluation Report

Microhole Motor Design for Doe’s Microhole Technology

Initiative

March 16, 2009

Prepared by:

Eric Twardowski

Dennis Tool Company

Houston, TX 


\section{Objective:}

To field test a new micromotor design as a result of previous small PDM motor reliability issues.

\section{Background:}

Previous tests conducted to evaluate drilling performance of a counter rotating tandem motor drilling system led to PDM problems and other miscellaneous issues with hole conditions. In order to move forward, two new motor designs were developed via Dennis Tool Company. After several shop testing sessions, one of the two designs was chosen for this test. Two prototype motors were manufactured and bench tested with nitrogen, water, and oil as the operating fluid.

\section{GTI-Catoosa location information:}

Test date: March 16-17, 2007

Operator: Gas Technology Institute

Location: S25 T21N R14E

County: Rogers

State: Oklahoma

Well: DM31, 5-1/2” casing inside of 7” casing to 164' depth, 3-1/2” diameter to 388' depth, 2-3/4” diameter to 402’ depth (see Appendix A)

\section{Equipment information:}

Rig: Sub Contractor Rig - Trailer mounted

Supervisor: Ron Bray / Scott Randolph

Pump: Gardner-Denver 3PE110, 5” stroke, 4” liner, 8gal/stroke @ 97\% efficiency

Motor: Prototype 2-1/8” diameter, right hand turning, micro-motor

Pilot bit: Dennis Tool Company, 2-7/8” PDC bit. 3 blades, 12 face cutters (0.315”

diameter) at $30^{\circ}$ backrake, 8 gauge cutters $(0.315$ ” diameter)

DownholeFilter: 2-1/8” O.D. x 48” long, 10 micron

Flow diverter: 2 x .098” sq. in. nozzles 
Circulating Sub: Circulating Sub

Drilling fluid: Clean water, 8.3 ppg

Formation: Sandstone, Limestone, Shale

\section{BHA - CLEANOUT RUN:}

2.900” diameter, 3 blade, tungsten carbide bit with 1-1/2"MT pin

1-1/2" MT box to box sub

1-1/2"MT pin to 2-1/16" Firestick box XO

2-1/16" Firestick drill pipe to surface

\section{BHA - TEST RUN:}

2.875” diameter PDC bit with 1-1/2"MT pin

2-1/8" diameter motor

2" diameter filter (10 micron)

Diverter Sub

Circulating Sub

XO (1-1/2"MT pin x 2-1/16" Firestick box)

Overall length of BHA - 7' (see appendix B)

2-1/16" Firestick drill pipe to surface

XO (2-1/16" Firestick pin x 3-1/2" I.F. box)

Filter Sub (3-1/2” I.F. pin x 3-1/2” I.F. box)

\section{Test summary:}

A cleanout run was conducted with a 2.900" tungsten carbide bit. This was performed to: A) ream the 2.75" diameter hole at bottom, B) circulate the hole and drill pipe clean. Because the test design has a low tolerance for solids, it was critical to circulate the pipe and hole with a high flowrate, making the system as clean as possible.

March 16, 2009

13:00 - The sub contractor rig arrived on location.

18:00 - Began picking up pipe with the tungsten carbide bit for the cleanout run.

18:30 - Ran the tungsten carbide bit and drill pipe to a depth of 348'. 
19:00 - Shutdown for the day and waiting for water tank to be filled on pump rig. March 17, 2009

7:00 - Filled water tank, picked up power swivel, circulated with high flow, washing down from 348' down to 388', reamed from 388' down to 402', circulated hole and pipe clean and pulled out of hole.

11:15 - Made up new BHA with motor (see appendix B), ran into hole (filling up the string). Bit nozzles were plugged with tapered rubber plugs to prevent backflow into motor while going to bottom.

12:15 - Attempt to drill, 30gpm, 800psi (surface pressure). Very slow progress. Noted leak on connection between filter sub and swivel. Stopped to tighten connection to swivel. Changed the filter (top filter sub) and noted approximately 50\% blockage on the filter, despite all previous work to circulate the pipe and hole clean. Ran back to hole bottom and attempted to drill (40pgm, 1600psi). Noted swivel was still leaking. ROP was extremely slow. Observed 400 psi pressure surge.

14:30 - Pulled out of hole. Removed BHA. Motor was found to be difficult to turn. Eventually, we were able to turn the motor by hand, but felt as though solids were preventing proper rotation. We dismantled the motor and cleaned components. This motor was then tested at the surface, but would not turn. This motor was removed and replaced with \#2 motor for surface test. After a surface test, this motor would turn by hand but did feel as though particles were inhibiting free rotation. The downhole filter (10 micron) was replaced. It was noted that the removed 10 micron filter was approximately $40 \%+$ blocked.

17:00 - Made up bit and ran into the hole without diverter or circulating subs in order to get all possible flow through the motor. Circulated at bottom.

18:30 - Attempted to drill (42gpm/2300psi) with no progress. Pulled out of the hole. Motor shaft would not turn by hand. Terminated the test.

\section{Conclusions:}

It is clear that although shop testing with clean oil, nitrogen, and clean water showed promising rpms, and torque, the motor is very susceptible to small particles. When disassembled after the test, small particles and surface corrosion among the tight 
tolerance components were noted. After cleaning the corrosion, these assemblies seemed to operate properly. Also noted on the number 2 motor was some damage to an internal drive component, likely caused by drill pipe rotation while the motor was in a locked condition.

Appendix A - Hole Condition prior to Catoosa Evaluation 03-16-09

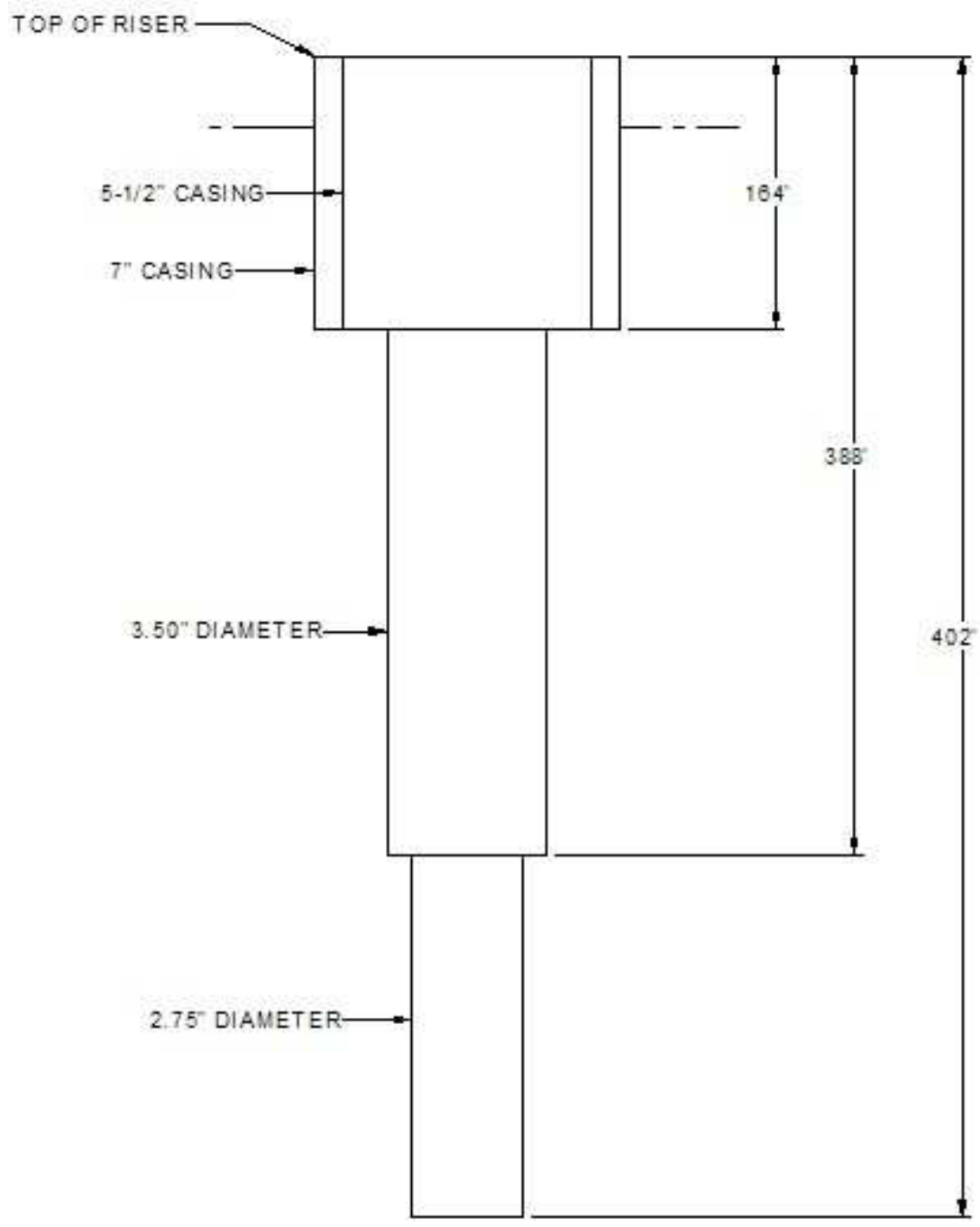

